\title{
Deflection and cracking behavior of SFRSCC beams reinforced with hybrid prestressed GFRP and steel reinforcements
}

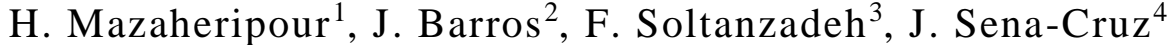

\begin{abstract}
In the present work, the deflection and cracking behavior of I-shaped cross-sectional beams of Steel Fiber Reinforced Self-Compacting Concrete (SFRSCC) reinforced in flexure with hybrid prestressed steel strand and glass fiber reinforced polymer (GFRP) bars was investigated. Combining prestressed GFRP bars of relatively low elasticity modulus, but immune to corrosion (located with a small concrete cover), with prestressed steel strand (with higher concrete cover to avoid corrosion), a good balance in terms of reinforcement effectiveness, ductility, durability and cost competitiveness can be obtained. The steel strand aims also to assure the necessary flexural strengthening of the beams if GFRP bars become ineffective in case of fire occurrence. This work presents and discusses the results obtained from the experimental study of the beams tested in flexure under monotonic loading conditions. Additionally, the predictive performance of the available formulation in the design codes for the case of Fiber Reinforced Concrete (FRC) and FRP reinforced Concrete (FRP-RC) was assessed to be used for the proposed hybrid system.
\end{abstract}

Keywords: Glass FRP bar, FRC, prestress, Deflection, Cracking

\footnotetext{
${ }^{1}$ PhD candidate, ISISE, Civil Eng. Dep., University of Minho, 4800-058 Guimarães, Portugal. h.mazaheripour@gmail.com

${ }^{2}$ Full professor, ISISE, Civil Eng. Dep., University of Minho, 4800-058 Guimarães, Portugal.barros@ @ivil.uminho.pt

${ }^{3}$ PhD candidate, ISISE, Civil Eng. Dep., University of Minho, 4800-058 Guimarães, Portugal. soltanzadehfaranak@gmail.com

${ }^{4}$ Associate professor, ISISE, Civil Eng. Dep., University of Minho, 4800-058 Guimarães, Portugal. jsena@ civil.uminho.pt
} 


\section{Introduction}

The interest in Fiber Reinforced Polymer (FRP) bars as internal reinforcements for concrete has been significantly increased during the last three decades due to the non-corrosive properties of FRP materials. Concrete elements internally reinforced with FRP bars, herein designated as FRP-RC, can, therefore, present higher durability than conventional steel RC elements. So far, many studies have been developed to evaluate the structural performance of FRP-RC structures [1-6]. Also, there are several codes and guidelines dedicated to the design of concrete member reinforced with FRP bars, which is an indicator of the interest of the construction industry in this technology [7-9]. USA, Canada, Switzerland and Germany are the countries that widely use FRP bars in bridge decks, in an attempt of overcoming the damages caused by corroded reinforcement due to the use of salts in de-icing process. FRP bars are, however, brittle materials, a property that decreases the ductility of FRP concrete members comparing to conventional steel RCs. This property may limit the use of FRP bars in many other applications of the construction industry. Additionally, the relatively low axial stiffness of FRP bars (e.g. Glass FRP), as well as the lower FRP-concrete bond strength $[10,11]$ when compared to steel-concrete bond, usually cause higher deformability and crack width under service loads. For these reasons, some attempts have been already done in order to improve the ductility of FRP-RCs, as well as to enhance their structural performance, mainly at Serviceability Limit State (SLS) conditions. These attempts can be mainly categorized as follow:

1) Using hybrid FRP reinforcing bars: the first idea of improving the ductility of FRP concrete members was to use hybrid FRP bars. These bars were fabricated by combining a set of yarns of two or more different types of fibers in an attempt to increase their ductile behavior in tension. By using this technique, a certain pseudo plasticity was given to the tensile behavior of these bars. Harris et al. in 1998 [12] carried out a group of concrete beam specimens reinforced by this type of hybrid FRP bars (CFRP material as core yarn and Aramid yarn surrounding the core part). The ductility was increased for the tested beams. However, complicated and costly manufacturing process resulted in limited practical applications.

2) Improving concrete properties: FRP reinforced structures are usually over-reinforced to fail by 
concrete crushing. Therefore, the ductility of FRP-RCs depends on concrete properties. Hence, increasing the concrete toughness may lead to ductility improvement. This can be assured by using Fiber (discrete fibers randomly distributed) Reinforced Concrete (FRC) instead of plain concrete [13]. Many researchers concluded that the structural behavior of FRP reinforced concrete beams can be improved by using FRC instead of plain concrete [12, 14-18].

3) Using hybrid FRP and steel bars: another explored strategy to improve the ductility and structural performance of FRP-RCs was the use of hybrid FRP and steel bars. According to the literature, this hybrid reinforcing system showed significant improvements in terms of beam's deformability under service load conditions, cracking behavior, and in service load carrying capacity [19-22].

In the present study, a combination of the second and third methods is used to improve the structural performance of GFRP-RC beams. For this purpose, the developed beams are made of Steel Fiber Reinforced Self-Compacting Concrete (SFRSCC) material and are reinforced in flexure by hybrid GFRP and steel bars. To better mobilize the relatively high tensile capacity of GFRP bars, they are placed near to the outer beam's tensile surface, while the steel reinforcement (as a material susceptible to corrosion) is placed with higher FRC cover to assure higher protection against corrosion. In addition to these characteristics, the following strategies are considered in order to increase as much as possible the structural performance:

- I-shaped cross section is proposed for such beam structure in order to have an optimized flexural performance, and take the benefit of having a higher flexural stiffness of section comparing to the rectangular cross sectional beam for the same volume of FRC material;

- Utilizing a SFRSCC with a post-cracking tensile capacity enough to avoid the use of steel stirrups, since they are the reinforcement elements more prone to corrosion [23]. This is more beneficial when I-shaped cross sectional beam is used, due to the shape of the cross section itself, and due to the difficulty of installing stirrups in relatively thin beam's web;

- GFRP bars and steel reinforcement are used in form of bonded prestressed bars in order to increase the flexural performance at SLS, and also, increasing the shear capacity of the beam.

The deflection and cracking behavior of such proposed RC type beam is investigated in the present 
study by analyzing the experimental results of SFRSCC beams reinforced in flexure with hybrid prestressed GFRP bars and steel strand, subjected to 4-point bending test under monotonic loading condition. Finally, a theoretical investigation is presented in order to predict the structural behavior of the proposed reinforcing system, with the aim of presenting design formulations.

\section{Experimental program}

\subsection{Materials}

\subsubsection{Steel strand and GFRP bars}

Two types of longitudinal reinforcements were used in the present experimental study: (i) ribbed surface GFRP bar of $12 \mathrm{~mm}$ diameter manufactured by Schöck Company and (ii) 9 and $15 \mathrm{~mm}$ nominal diameter of steel strand of grade 1725 (formed by uncoated seven-wires), which is currently used in construction industry (prestressing system). The GFRP bar's ribs have a constant height of $6 \%$ of bar diameter and rib's spacing of about $8.5 \mathrm{~mm}$. Some nominal mechanical properties of the reinforcements, based on the information given by the manufacturers, are included in Table 1.

\subsubsection{Steel Fiber Reinforced Self-Compacting Concrete (SFRSCC)}

The SFRSCC used in the present experimental program was prepared based on the mix method developed by Soltanzadeh et al. [23]. The used materials were cement (CEM II 52.5R), fly ash class F, limestone filler, superplasticizer (Glenium SKY 617, is a second generation of superplasticizer based on polycarboxylate ether (PCE)), water, three types of aggregates (containing fine and coarse river sand, and crushed granite) and hooked end steel fibers of $33 \mathrm{~mm}$ in length, aspect ratio of 65 and yield stress of $1100 \mathrm{MPa}$. The mix composition is given in Table 2, and more details can be found in [23]. From the compression tests carried out with 25 cylinder specimens of $150 \mathrm{~mm}$ diameter and $300 \mathrm{~mm}$ height (at least two cylinders from each mix batch for casting the beam specimens that are described in the next section), according to ASTMC39 and C469, respectively, an average compressive strength of 73.13 $\mathrm{MPa}$ (with a coefficient of variation (CoV) of 6\%) and an average Young's modulus of $35.4 \mathrm{GPa}$ (with a $\mathrm{CoV}$ of 3\%) were obtained. In addition, three cylinder specimens were tested in deformation control for capturing the whole stress-strain relationship of SFRSCC in compression. With regard to the behavior of SFRSCC in tension, which is the characteristic most benefited by fiber reinforcement, five 
simply supported notched beams of $150 \times 150 \mathrm{~mm}^{2}$ cross section and $600 \mathrm{~mm}$ in length were subjected to three point loading conditions to characterize and classify of the post-cracking behavior of SFRSCC according to CEB-FIP Model Code 2010 [24]. The tests were carried out according to the same recommendations, i.e. Model Code 2010. Nominal values of the flexural properties of SFRSCC can be determined by considering the diagram of the applied force $(F)$ versus the Crack Mouth Opening Displacement $(C M O D)$. The residual flexural tensile strengths, $f_{R, j}$ are evaluated from the $F-C M O D$ relationships, as follows:

$$
f_{R, j}=\frac{3}{2} \frac{F_{j} l}{b_{n} h_{s p}^{2}}
$$

where $F_{j}$ is the applied load corresponding to $C M O D_{j}\left(C M O D_{1}=0.5 \mathrm{~mm}, C M O D_{2}=1.5 \mathrm{~mm}\right.$, $C M O D_{3}=2.5 \mathrm{~mm}$ and $\left.C M O D_{4}=3.5 \mathrm{~mm}\right), l$ is the notched beam's span, while $b_{n}$ and $h_{s p}$ is the width of the cross section and the distance between the notch tip and the top of the beam, respectively (being $h_{s p}=115 \mathrm{~mm}$ ). The average residual flexural tensile stress parameters of SFRSCC are included in Table 3.

\subsection{Beams: geometry, reinforcements and prestress levels}

A total of ten I-shaped cross-sectional SFRSCC beams reinforced by passive or prestressed GFRP bars, and passive or prestressed steel strand, simply supported, was subjected to four-point bending test under monotonic and fatigue loading conditions. The experimental variables were the reinforcement ratio of hybrid GFRP/steel strand and the level of prestress in GFRP bars $\left(P_{p f}\right)$. Note that the prestress level of GFRP bars $\left(f_{f}^{\text {pre }}\right)$ is calculated based on a percentage of its ultimate tensile stress $\left(f_{f u}\right)$, and prestress level of steel strand ( $\left.f_{s}^{\text {pre }}\right)$ is calculated based on a percentage of its yielding stress $\left(f_{s y}\right)$. The tests were carried out in two groups. The Group A included three prestressed I-shaped beams (IB) reinforced by non-prestressed GFRP bars and prestressed steel strand, while the Group B was composed by five prestressed I-shaped beams (IB) where the prestress was applied to both reinforcements. Each group also included one I-shaped beam with no prestress applied neither to GFRP bars nor steel strand. The identification, reinforcement data, and the prestress level are indicated in Table 4 for both groups 
of tests. Additionally, dimension of the beams and their reinforcement details are shown in Figure 1. In Group B, IB7 and IB9 beams (with the same configurations as IB6 and IB8, respectively) as well as IB10 were used to be subjected to fatigue loading conditions. After accomplishment of two million fatigue loading cycles, the beams were subjected to monotonic loading condition up to failure. The results of the fatigue tests are not reported in the present work, however, the monotonic test result of IB10 after fatigue cycles is discussed in section 4.

\subsection{Test setup, test procedure and monitoring system}

As already referred, the beam specimens were subjected to a four-point bending test configuration by using a servo-hydraulic actuator of $500 \mathrm{kN}$ loading capacity under monotonic loading condition. The points loading distance (indicated by "Pure bending zone" in Figure 2) was $750 \mathrm{~mm}$ for the Group A of the beams, while this value was decreased to $500 \mathrm{~mm}$ for the Group B. The tests were displacementcontrolled by imposing a speed of $0.01 \mathrm{~mm} / \mathrm{s}$ to the piston of the actuator. Five Linear Variable Differential Transducers (LVDTs) were installed along the span length of the beam, according to the schematic representation in Figure 2. This figure also includes the disposition of the nine strain gauges installed on the materials for measuring their strain during loading (indicated as 'SG' for GFRP bars, 'SGst' for steel strand, and 'SGc' for SFRSCC).

\subsection{Pre-strain losses}

In Group A, the applied prestress force was controlled using the force value registered by the load cells installed at the extremity of the bars, while in the Group B the prestressing application was performed by monitoring both the force in the load cell and the strains recorded by the strain gauges installed along the reinforcements. Table 5 includes the average results of the pre-strain of the reinforcements recorded by the strain gauges ( $\varepsilon_{s}^{p r e}$ for steel strand and $\varepsilon_{f}^{p r e}$ for GFRP bars) at pulling, releasing, and testing days. The pre-strain losses in the reinforcements were computed based on the measured values of strain at pulling and testing days. These pre-strain losses (indicated in Table 5) are mainly due to the elastic deformation of HFRRC beams, creep and shrinkage of SFRSCC, and the relaxation of the reinforcements. The average pre-strain losses at the day of testing was about $13.6 \%$ and 9.8\% regarding the pre-strain at the pulling day for GFRP bars and steel strand, respectively. 


\section{Theoretical investigation}

\subsection{Balanced reinforcement ratio}

In conventional steel RC beams, the balanced steel reinforcement ratio, $\rho_{s b}$, is defined as a failing condition that concrete crushing and yielding of steel occur simultaneously. Equivalently, when steel bars are replaced by FRP bars (in FRP-RC beams), the balanced FRP reinforcement ratio, $\rho_{f b}$, is defined by simultaneous occurrence of concrete crushing and tensile rupture of FRP bars. In hybrid FRP-steel reinforced beams, the balanced reinforcement ratio can be theoretically defined as a failure condition where concrete crushes, tensile steel yields, and FRP ruptures in tension at the same time. However, this situation is almost impractical. Therefore, as it was defined earlier by Lau et al. [19], it is more practical to define the balanced reinforcement ratio in hybrid FRP-steel RC beam as a failure condition that concrete crushing and the rupture of FRP bars occur at the same time, while the steel reinforcement has already yielded. From this standpoint, the hybrid balanced reinforcement ratio of FRP-steel RC beam, $\rho_{h b}$, is calculated using the following equation [19, 21]:

$$
\rho_{h b}=\rho_{f b}-m_{s} \rho_{s}
$$

with $\rho_{f b}$ given by (ACI 440.1R-06 [7])

$$
\rho_{f b}=\alpha_{1} \beta_{1} \frac{f_{c}^{\prime}}{f_{f u}} \frac{E_{f} \varepsilon_{c u}}{E_{f} \varepsilon_{c u}+f_{f u}}
$$

where $\alpha_{1}$ and $\beta_{1}$ are the parameters defining the rectangular stress block, as illustrated in Figure 3. The parameter $\alpha_{1}$ is the ratio between the equivalent average concrete compressive stress and the concrete compressive strength, $f_{c}{ }_{c}$, while the parameter $\beta_{1}$ is a factor relating the depth of equivalent rectangular concrete compressive stress block to neutral axis depth $c$ ( $c_{b}$ in the balanced conditions). In Eq. (3) $\varepsilon_{c u}$ is the ultimate compressive strain in concrete (it is assumed to be equal to 0.0035). Moreover, the second term on the right side of Eq. (2) intends to simulate the presence of yielded steel reinforcement in the balanced section, in which $m_{s}$ is

$$
m_{s}=\frac{d_{s}}{d_{f}} \frac{f_{s y}}{f_{f u}}
$$


where $d_{s}$ and $d_{f}$ are the internal arm of steel and FRP reinforcement, respectively, as represented in Figure 1.

For the case of the present study, Eq. (2) has to be modified by considering the effect of prestressing in FRP and steel, as well as the post-cracking response of SFRSCC. By assuming that plane section remains plane during the loading process of the beam (Bernoulli's hypothesis), the strain compatibility shown in Figure 3 allows the determination of the $c_{b} / d_{f}$ ratio in terms of the installed strains at balanced section:

$$
\frac{c_{b}}{d_{f}}=\frac{\varepsilon_{c u}}{\varepsilon_{c u}+\varepsilon_{f u}-\varepsilon_{f}^{p r e}}
$$

Note that the possible losses of pre-strain due to the creep and shrinkage of SFRSCC, elastic shortening of SFRSCC, etc., are all included in the value assigned to $\varepsilon_{f}^{\text {pre }}$. From the equilibrium condition at the balanced section of the hybrid SFRSCC beam, the following equation can be derived:

$$
\alpha_{1} \beta_{1} f_{c}^{\prime}\left(\beta_{2} b\right) c_{b}=\rho_{f} b d_{f} f_{f u}+\rho_{s} b d_{s} f_{s y}+F_{f r, b}
$$

where $F_{f r, b}$ is the tensile force due to the SFRSCC in tension at the balanced section condition, and $\beta_{2}$ is the parameter that takes into account the particular geometry of the adopted I shape cross section, giving by

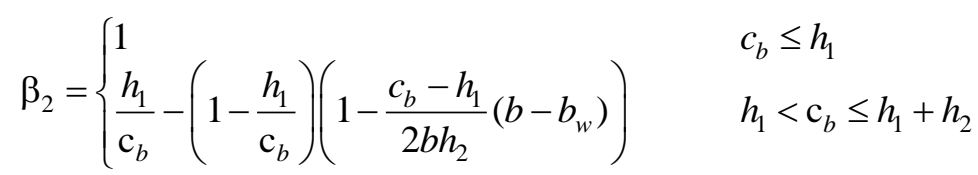

By considering an equivalent average value of crack tensile stress of SFRSCC over the distance $h-c_{b}$ at the balanced section (i.e. $\bar{\sigma}_{c t, b}^{c r}$ shown in Figure 3), $F_{f r, b}$ becomes

$$
F_{f r, b}=\bar{\sigma}_{c t, b}^{c r}\left(\rho_{c}-\frac{c_{b}}{d_{f}} \beta_{2}\right) b d_{f}
$$

with

$$
\rho_{c}=\frac{A_{g}}{b d_{f}}
$$

where $A_{g}$ is the gross area of the beam cross section. By substituting Eq. (8) into Eq. (6), and taking $c_{b} / d_{f}$ from Eq. (5), the value of $\rho_{f}$ is found as the balanced reinforcement ratio for hybrid FRP-steel 
SFRSCC prestressed beam, $\rho_{h b}$, giving by

$$
\rho_{h b}=\beta_{2}\left(\frac{\alpha_{1} \beta_{1} f_{c}^{\prime}}{f_{f u}}+m_{f r}\right) \frac{\varepsilon_{c u}}{\varepsilon_{c u}+\varepsilon_{f u}-\varepsilon_{f}^{p r e}}-m_{s} \rho_{s}-m_{f r} \rho_{c}
$$

where

$$
m_{f r}=\frac{\bar{\sigma}_{c t, b}^{c r}}{f_{f u}}
$$

The value of $\bar{\sigma}_{c t, b}^{c r}$ can be estimated using the following integral

$$
\bar{\sigma}_{c t, b}^{c r}=\frac{G_{f, u}}{\varepsilon_{f u}}
$$

where $G_{f, u}$ is the spent mode I fracture energy of SFRSCC at balanced section when $\varepsilon_{f}=\varepsilon_{f u}$ (or when the concrete compressive strain reaches its ultimate value, $\varepsilon_{c u}$ ).

\subsection{Nominal flexural strength}

If the hybrid reinforced SFRSCC prestressed beam is under-reinforced, i.e. $\rho_{f}<\rho_{h b}$, a tensioncontrolled section condition occurs as a result of FRP bars rupture before crushing of the concrete (i.e. $\varepsilon_{f}=\varepsilon_{f u}$ and $\left.\varepsilon_{c}<\varepsilon_{c u}=0.0035\right)$. Conversely, if $\rho_{f} \geq \rho_{h b}$, a compression-controlled section condition occurs in which the concrete crushes without having failure at the FRP bars (i.e. $\varepsilon_{f}<\varepsilon_{f u}$ and $\left.\varepsilon_{c}=\varepsilon_{c u}=0.0035\right)$. Note that in both cases is assumed that the steel strand has already yielded. These two nominal failing conditions are illustrated in Figure 4. If the linear distribution of strain along the depth of the section is adopted (Bernoulli's hypothesis), the calculation of the nominal flexural strength incorporates two unknown parameters: (i) the level of neutral axis (i.e. $c$ ) and (ii) the tensile strain of GFRP bars for "Condition 1" or the compressive strain of SFRSCC for "Condition 2". The neutral axis depth, $c$, can be efficiently approximated by equalizing the variation of force between the section at the nominal failing condition and the balanced failing condition:

$$
\left(F_{c}^{\mathrm{SFRSCC}}-F_{c, b}^{\mathrm{SFRSCC}}\right) \cong\left(F_{f}-F_{f, b}\right)+\left(F_{f r}-F_{f r, b}\right)
$$

where $F_{c}^{\text {SFRSCC }}$ and $F_{f r}$ are the compressive force and the tensile force assured by SFRSCC at nominal 
failing condition, while $F_{f}$ represent the tensile force due to FRP bars at this section. Note that it is assumed the steel has yielded, hence, the tensile stress variation in this reinforcement is null. Eq. (13) can be expressed by

$$
m_{1} f_{c}^{\prime}\left(\beta_{2} b\right)\left(c-c_{b}\right) \cong m_{2} f_{f u} b d_{f}\left(\rho_{f}-\rho_{h b}\right)+\bar{\sigma}_{c t, b}^{c r}\left(\beta_{2} b\right)\left(c-c_{b}\right)
$$

where $m_{1}$ and $m_{2}$ are the modification factors that take into account, respectively, the change of SFRSCC compressive rectangular stress block and the tensile stress of FRP bar, at the nominal failing condition with respect to the balanced failing condition. Eq. (14) can be rewritten as follow

$$
c=c_{b}+\gamma\left(\rho_{f}-\rho_{h b}\right)
$$

with

$$
\gamma=\frac{m_{2} f_{f u}}{\beta_{2}\left(m_{1} f_{c}^{\prime}-\bar{\sigma}_{c t, b}^{c r}\right)} d_{f}
$$

where $c_{b}$ and $\rho_{f b}$ can be calculated, respectively, by Eqs. (5) and (10). The definition of the modification factors, $m_{1}$ and $m_{2}$ are not straightforward since they are dependent on the level of neutral axis, $c$. But, in order to proceed with the calculation of $c$ by Eq. (15), they can be approximated by the following equations, depending on the ratio between $\rho_{f}$ and $\rho_{h b}$ :

$$
m_{1}=\left\{\begin{array}{ll}
\left(1+\rho_{f} / \rho_{h b}\right) \alpha_{1} \beta_{1} & \rho_{f} \leq \rho_{h b} \\
\alpha_{1} \beta_{1} & \rho_{f}>\rho_{h b}
\end{array}, \quad m_{2}= \begin{cases}1 & \rho_{f} \leq \rho_{h b} \\
\rho_{h b} / \rho_{f} & \rho_{f}>\rho_{h b}\end{cases}\right.
$$

The parameter $\beta_{1}$ in Eq. (17) corresponds to the compressive strain of $\varepsilon_{c u}$, and the parameter $\beta_{2}$ is calculated for the value of $c_{b}$ from Eq. (7).

By having obtained the value of $c$, the nominal flexural strength of the hybrid reinforced SFRSCC prestressed beam is calculated under these two conditions:

- Condition $1\left(\rho_{f}<\rho_{b h}\right)$ : considering the strain compatibility, the concrete compressive strain at top surface is

$$
\varepsilon_{c}=\frac{\varepsilon_{f u}-\varepsilon_{f}^{p r e}}{\left(d_{f}-c\right)} c
$$

Since the tensile strain of FRP equals to its ultimate value, the average tensile stress of SFRSCC 
is taken to be equal to the respective value at the balanced section (i.e. $\bar{\sigma}_{c t, b}^{c r}$, from Eq. (12)). Hence, the nominal flexural strength can be determined by summation of moments about the centroid of rectangular SFRSCC compressive stress block:

$$
M_{n}=F_{s y} \cdot\left(d_{s}-\frac{\beta_{1} c}{2}\right)+F_{f u} \cdot\left(d_{f}-\frac{\beta_{1} c}{2}\right)+\bar{\sigma}_{c t, b}^{c r}\left(A_{g}-c \cdot \beta_{2} b\right) \cdot\left(d_{f r}-\frac{\beta_{1} c}{2}\right)
$$

where $\beta_{2}$ is calculated by Eq. (7) for the value $c$, which replaces $c_{b}$. In addition, $d_{f r}$ is defined as distance of the resultant of the tensile force due the fiber reinforcement, $F_{f r}$ (defined in Figure 3), from the top surface of the section, which may be approximated with an acceptable accuracy using

$$
d_{f r}=\frac{1}{2}(h+c)
$$

- Condition $2\left(\rho_{f}>\rho_{b h}\right)$ : considering the similitude of triangles, the total tensile strain of FRP bars is determined as

$$
\varepsilon_{f}=\left(\frac{d_{f}}{c}-1\right) \varepsilon_{c u}+\varepsilon_{f}^{p r e}
$$

Hence, the nominal flexural strength can be determined by summation of moments about the centroid of SFRSCC rectangular compressive stress block:

$$
M_{n}=F_{f} \cdot\left(d_{f}-\frac{\beta_{1} c}{2}\right)+F_{s y} \cdot\left(d_{s}-\frac{\beta_{1} c}{2}\right)+\bar{\sigma}_{c t}^{c r}\left(A_{g}-c \cdot \beta_{2} b\right) \cdot\left(d_{f r}-\frac{\beta_{1} c}{2}\right)
$$

where $\bar{\sigma}_{c t}^{c r}$ is the average crack tensile stress of SFRSCC that can be estimated by Eq. (12) for $\varepsilon_{f u}$ equal to $\varepsilon_{f}$ obtained by Eq. (21), and calculating the spent mode I fracture energy of SFRSCC at when the concrete compressive strain reaches its ultimate, i.e. $\varepsilon_{c}=\varepsilon_{c u}$.

\subsection{Stress-strain constitutive law of the intervening materials}

The average experimental trend obtained by performing the uniaxial compression tests on SFRSCC cylinders is plotted in Figure 5a. The pre-peak phase of this experimental trend can be sufficiently approximated by a bi-linear constitutive law (due to the high compressive nature of the developed SFRSCC) that is simply expressed by the following equation: 


$$
\sigma_{c}\left(\varepsilon_{c}\right)= \begin{cases}E_{c} \varepsilon_{c} & \varepsilon_{c} \leq \varepsilon_{c p} \\ f_{c}^{\prime} & \varepsilon_{c}>\varepsilon_{c p}\end{cases}
$$

where $\varepsilon_{c p}$ defines the threshold of plastic limit for SFRSCC in compression (shown in Figure 5a), which is taken as $f_{c}^{\prime} / E_{c}$. In addition, the ultimate compressive strain of SFRSCC is limited to $0.35 \%$ [25]. By taking this bi-linear compressive stress-strain law defined in Eq. (23), the equivalent rectangular compressive stress block can be defined by means of the parameters $\alpha_{1}$ and $\beta_{1}$, which are computed by

$$
\alpha_{1}=\left\{\begin{array}{ll}
\frac{1}{2} \frac{E_{c} \varepsilon_{c}}{f_{c}^{\prime}} \frac{1}{\beta_{1}} & \varepsilon_{c} \leq \varepsilon_{c p} \\
\left(1-\frac{1}{2}\left(\frac{\varepsilon_{c p}}{\varepsilon_{c}}\right)\right) \frac{1}{\beta_{1}} & \varepsilon_{c p}<\varepsilon_{c} \leq \varepsilon_{c u}
\end{array} \quad, \quad \beta_{1}= \begin{cases}\frac{2}{3} & \varepsilon_{c} \leq \varepsilon_{c p} \\
1-\left(\frac{\varepsilon_{c p}}{\varepsilon_{c}}\right)+\frac{1}{3}\left(\frac{\varepsilon_{c p}}{\varepsilon_{c}}\right)^{2} & \varepsilon_{c p}<\varepsilon_{c} \leq \varepsilon_{c u}\end{cases}\right.
$$

when the compressive strain reaches its ultimate value (balanced failing condition or nominal failing condition when $\rho_{f}>\rho_{h b}$ ), the term $\alpha_{1} \cdot \beta_{1}$ gets the maximum value of 0.714 for $\varepsilon_{c}=\varepsilon_{c u}=0.35 \%$ (being $\alpha_{1}=0.949$ and $\beta_{1}=0.752$ ).

The tensile stress-strain diagram of SFRSCC is defined based on the average tensile stress-crack opening diagram that was obtained by performing an inverse analysis. The inverse analysis consisted in applying a numerical strategy similar to the one described in [26], where the tensile stress-CMOD defining the tensile behavior of SFRSCC was assessed by fitting the experimental force-CMOD obtained from the notched beams. The obtained stress-crack opening diagram is plotted in Figure 5c, that was converted in a 4-linear tensile stress-strain diagram by considering the structural characteristic length $l_{c s}$ [24]. Based on the CEB-FIB Model Code 2010 [24], the $l_{c s}$ can be taken as the smaller value amongst (i) the average crack spacing and (ii) the distance between the neutral axis and the tensile side of the section. For case of the tested beams, $l_{c s}$ is taken as the average crack spacing (i.e. $S_{c r}$ ) that will be discussed and computed later on (see section 3.6). The obtained tensile stress-strain diagram is plotted in Figure 5b. The corresponding point values that define this 4-linear tensile stress-strain and tensile stress-crack opening diagrams of SFRSCC are included in the figure. Additionally, the tensile stress-strain of the steel strand and GFRP bars are plotted in Figure 5d and 5e, respectively. 


\subsection{Sectional analysis by using moment-curvature approach}

The balanced reinforcement ratio and the nominal flexural strength defined in the previous sections can be obtained by using a sectional analysis. In the present work, the software named DOCROS (Design Of CROss Section) that calculates moment-curvature relation, as well as strain distribution along section by taking into account the constitutive laws of materials, the kinematic and the equilibrium conditions, was used (More details about DOCROS software and their constitutive models can be found from the studies carried out in [27-29]). For the present purpose, the cross section is discretized in layers of $5 \mathrm{~mm}$ (numerical section shown in Figure 3), and the constitutive models of the intervening materials (shown in Figure 5) are assigned to their respective layers. In this software, the compressive stress-strain relationship of the SFRSCC is simulated according to the model proposed elsewhere [30], while the 4linear tensile stress-strain plotted in Figure 5b is considered for SFRSCC tensile behavior after cracking.

The balanced reinforcement ratio, $\rho_{h b}$, was found by changing the value of $\rho_{f}$ in DOCROS software for a situation that the compressive strain at top surface is $\varepsilon_{c u}=0.0035$, and simultaneously the tensile strain of FRP bars equals to $\varepsilon_{f u}$. On the other hand, the nominal flexural strength was found for value of the applied moment that causes failing of the beam by either the tensile rupturing of FRP bars (i.e. $\varepsilon_{f}+\varepsilon_{f}^{p r e}=\varepsilon_{f u}$ ) or crushing of SFRSCC in compression (i.e. $\varepsilon_{c}=0.0035$ ). Note that the values of pre-strain at testing day (included in Table 5) are assigned to the corresponding layers for FRP bars and steel strand, which conducts to negative value for curvature at the initiation of the analysis.

The calculated values of the balanced reinforcement ratio $\left(\rho_{h b}\right)$ and the nominal flexural strength ( $M_{n}$ ) of the tested beams by the proposed equations in the previous section and by DOCROS software are included in Table 6. The results of nominal flexural strength from the proposed equations are in a good agreement with the results obtained from DOCROS software. Additionally, the values of the depth of neutral axis calculated by Eq. (15) are quite close to those determined by DOCROS. This proofs that the analytical formulation is an efficient tool for design purposes.

Based on the calculated balanced reinforcement ratio $\rho_{h b}$, the first three beams (i.e. IB1, IB2 and IB3) are almost balanced reinforced beams, the IB4 beam is over-reinforced, and the beams of Group B are all under-reinforced. Moreover, with aid of DOCROS software, an upper limit value for FRP 
reinforcement ratio (i.e. $\rho_{f}^{u p}$ ) was provided in Table 6 for the beams in group A, in which for $\rho_{f}>\rho_{f}^{u p}$ , the concrete crushing occurs prior to yielding of steel strand in tension. This upper limit value is significantly higher than the calculated hybrid balanced reinforcement ratio, and it increased by increase in the level of prestress in steel strand. It should be noticed that the yielding of steel strand for underreinforced beams in group B is always guaranteed due to the fact that $\varepsilon_{f u} \gg \varepsilon_{s y}$.

\subsection{Theoretical deflection}

To theoretically predict the deflection relationship of the IB specimens, two methods are followed in this study:

1) The beam is discretized in Euler-Bernoulli beam element of 2 nodes. Then, the moment-curvature relationship (that was obtained from DOCROS software) is assigned to each element to compute the flexural stiffness by using a matrix displacement approach. This analysis procedure is done by using Def-DOCROS software, which is described more in detail elsewhere ([27, 31]);

2) Using a direct method similar to the one suggested by ACI318, which was followed by subsequent ACI guidelines for concrete structures reinforced by FRP bars (ACI440-1R [7]), and prestressed concrete structures with FRP tendons (ACI440-4R [32]). Based on this method, an effective moment of inertia $\left(I_{\text {eff }}\right)$ of beam section is determined using the moment of inertia of the cracked section ( $\left.I_{c r}\right)$ at failure, which corresponds to the maximum moment $\left(M_{n}\right)$. This method is explained in this section.

Based on the traditional mechanics of materials, the maximum deflection of the tested beam, $D_{\max }$ , is determined by

$$
D_{\max }=\frac{M_{a}}{6 E_{c} I_{g}}\left(\frac{3}{4} L^{2}-a^{2}\right)
$$

where $I_{g}$ is the gross moment of inertia of un-cracked section, and $E_{c}$ is the elastic modulus of SFRSCC (average value obtained from the cylinder specimens, see section 2.1.2). Further, $L$ and $a$ are the beam and shear spans, respectively. ACI suggests to replace $I_{g}$ by the effective moment of inertia ( $I_{\text {eff }}$ ) of the cracked beam to obtain its deflection in cracked stage. Hence, $I_{\text {eff }}$ is calculated using (ACI440-1R [7]): 


$$
I_{e f f}= \begin{cases}I_{g} & M_{a} \leq M_{c r} \\ I_{c r}+\left(\beta_{d} I_{g}-I_{c r}\right)\left(\frac{M_{c r}}{M_{a}}\right)^{3} & M_{a}>M_{c r}\end{cases}
$$

where $\beta_{d}$ is a factor that takes into account the relatively smaller tension stiffening effect when using FRP reinforcements, giving by

$$
\beta_{d}=\frac{1}{5}\left(\frac{\rho_{f}}{\rho_{f b}}\right) \leq 1.0
$$

In Eqs. (34) and (35), the parameter $M_{a}$ is the maximum moment of beam for each level of loading, and $M_{c r}$ is the cracking moment of the beam that can be calculated by

$$
M_{c r}=\frac{2\left(f_{c t}+\sigma_{c, m}^{p r e}\right) I_{g}}{h}
$$

where $\sigma_{c, m}^{p r e}$ is the compressive stress introduced in the bottom surface of the beam's cross section due to the eccentrically applied prestress force:

$$
\sigma_{c, m}^{p r e}=\sigma_{c}^{p r e}+\frac{M_{p} h}{2 I_{g}}
$$

where

$$
\sigma_{c}^{p r e}=\frac{N_{p s}+N_{p f}}{A_{g}}
$$

and

$$
M_{p}=N_{p s}\left(d_{s}-\frac{1}{2} h\right)+N_{p f}\left(d_{f}-\frac{1}{2} h\right)
$$

The parameters $N_{p s}$ and $N_{p f}$ are, respectively, the axial forces due to prestress in steel strand and FRP bars, which were previously given in Table 4 . The concept of the proposed effective moment of inertia $\left(I_{\text {eff }}\right)$ by Eq. (26) is schematically illustrated in Figure 6a (shown by dotted line) for a concrete member reinforced with FRP bars (FRP-RC). As shown, this equation presents the decrease of $I_{\text {eff }}$ by increasing the applied moment. Before reaching the cracking moment, i.e. $M_{a}<M_{c r}$, it is assumed that $I_{\text {eff }}=I_{g}$ . After crack initiation, $I_{e f f}$ decreases with the increase of the ratio between the cracking moment and the applied moment $\left(M_{c r} / M_{a}\right)$, getting the moment of inertia of the cracked section, $I_{c r}$, at the flexural 
failing. According to the ACI 440-1R-06 design guidelines, for FRP-RC beams, the moment of inertia of the cracked section $\left(I_{c r}\right)$ can be determined by

$$
I_{c r}=\frac{b c^{3}}{3}+n \cdot A_{f}\left(d_{f}-c\right)^{2}
$$

where $n$ is the ratio of the modulus of elasticity of FRP bars to the modulus of elasticity of concrete ( $\left.E_{f} / E_{c}\right)$. However, in this study, the moment of inertia of the cracked hybrid SFRSCC beam at failure is determined by calculating the curvature of the cracked section at failure, giving by

$$
I_{c r}^{h}=\frac{M_{n}}{E_{c} \chi_{c r}^{h}}=\frac{M_{n}\left(d_{f}-c\right)}{E_{c}\left(\varepsilon_{f}-\varepsilon_{f}^{p r e}\right)}
$$

where $\chi_{c r}^{h}$ is the curvature of beam corresponding to the nominal flexural strength (i.e. $M_{n}$ ). The nominal flexural strength can be calculated using Eq. (19) or Eq. (22) depending on being under or overreinforced section conditions, respectively. Further, the FRP tensile strain $\varepsilon_{f}$, is calculated by Eq. (21) when $\rho_{f}>\rho_{h b}$, and it is equal to FRP ultimate tensile strain when $\rho_{f} \leq \rho_{h b}$. Note that in the above equation, the value of $c$ is computed using Eq. (15), which is the depth of the neutral axis for $M_{a}=M_{n}$ in the section with maximum moment.

For case of plain concrete in FRP-RC beam, the tensile stress of concrete drops to almost zero after crack initiation (following typical tension-softening of plain concrete), which introduces significant loss in the effective moment of inertia, $I_{\text {eff }}$, after crack initiation. Additionally, the axial stiffness of FRP bars, as well as their bond performance to concrete are normally lower than conventional steel bars. Therefore, the tension-stiffening exhibited by FRP bars at crack initiation is less than steel bars. For this reason, the ACI committee 440 recommends the coefficient $\beta_{d}$ that is defined by the simple relation given in Eq. (27) depending on the ratio $\rho_{f} / \rho_{h b}$, in which the decrease level of the effective moment of inertia is governed by the coefficient $\beta_{d}$, as illustrated in Figure 6a.

Conversely, for the case of hybrid reinforced SFRSCC beam, SFRSCC material provides high residual tensile stress after crack initiation (normally following a slight tension-hardening branch in its direct tension behavior as shown by $\mathrm{P} 2$ in Figure $5 \mathrm{~b}$ ), which reduces the decreasing rate of the effective moment of inertia at cracking stage. This trend in both FRP-RC beam and hybrid SFRSCC beam is 
schematically compared in Figure 6b. Due to this difference, the function that reduces the effective moment of inertia, presented in Eq. (26), cannot be directly used for case of hybrid SFRSCC beam when $M_{a}>M_{c r}$. In order to adjust Eq. (26) for this type of beams, the concrete tensile strength $\left(f_{c t}\right)$ is replaced by the limit of proportionality $\left(f_{c t, L}\right)$, which is included in Table 3 , and calculated using Eq. (1) for $F_{j}$ corresponding to $C M O D=0.05 \mathrm{~mm}$ in the standard notched beam test. Hence, in Eq. (26) the cracking moment is now replaced by $M_{c r}^{L}$, which is computed by the following equation

$$
M_{c r}^{L}=\frac{2\left(f_{c t, L}+\sigma_{c, m}^{p r e}\right) I_{g}}{h}
$$

The difference between considering $M_{c r}$ or $M_{c r}^{L}$ in Eq. (26) is shown in Figure 6a and b. With this strategy, the effective moment of inertia is assumed $I_{g}$ for $M_{a} \leq M_{c r}^{L}$, which introduces a slight error in calculation of deflection for $M_{c r}<M_{a} \leq M_{c r}^{L}$, however, it gives accurate results for $M_{a}>M_{c r}^{L}$, as it will be discussed later in section 4 . Based on the above explanation, the following equation is proposed for the calculation of the effective moment of inertia for the proposed hybrid system:

$$
I_{e f f}^{h}= \begin{cases}I_{g} & M_{a} \leq M_{c r}^{L} \\ I_{c r}^{h}+\left(\beta_{d} I_{g}-I_{c r}^{h}\right)\left(\frac{M_{c r}^{L}}{M_{a}}\right)^{3} & M_{a}>M_{c r}^{L}\end{cases}
$$

where the value of $\beta_{d}$ is recommended to be assumed unit value for case of the hybrid SFRSCC beams proposed in this study. It should be noticed that $I_{e f f}^{h}$ is also influenced by the propagation of flexureshear cracks in shear span, as it is discussed in the next section.

\subsubsection{Effect of shear crack propagation on the effective moment of inertia}

For case of reinforced FRC beams without shear reinforcements, the effective moment of inertia of the member calculated by Eq. (35) is influenced by the propagation of shear cracks in flexure-shear zones. This is attributed to the fact that the average curvature of SFRSCC beam in shear span gets higher magnitude rather than when the beam with no fibers, and it is shear reinforced with steel stirrups. This can be explained by the following two aspects:

i. When compared to the conventional beams of plain concrete shear reinforced with steel stirrups, 
FRC beams do not including steel stirrups, as is the case of the present beams, develop larger curvature for the same applied moment. For assuring force equilibrium in the crack section of a FRC beam, the neutral axis needs to progress further due to the tensile softening character of the post-tensile behavior of FRC instead of the tensile hardening effect provided by steel stirrups.

ii. In the shear span of FRC beams, the shear component in the crack face promotes the occurrence of micro-spalling of the paste at the exit point of the fibers [33], whose occurrence introduces an instantaneous increase of crack opening with a direct consequence on the decrease of the post-cracking tensile capacity of the cracked section.

While experimental results are not available for more reliable approach, the decrease level in the moment of inertia caused by these effects are simulated by the second linear parcel introduced in Eq. (35) for $M_{a}>M_{c d}$, where $M_{c d}$ defines the applied moment corresponding to the nominal shear strength of the beam only due to the concrete, $V_{c d}$. This can be taken as the values recommended by the CEB-FIB Model code 2010 (the calculated values are given in Table 7), however, it should not be obviously taken smaller than $M_{c r}^{L}$. This reduction is schematically illustrated in Figure 6c. The modified equation of the effective moment of inertia for SFRSCC reinforced beams considering the increase in the curvature of beam due to the cracks in shear span is given by

$$
I_{e f f}^{h}= \begin{cases}I_{g} & M_{a} \leq M_{c r}^{L} \\ I_{c r}^{h}+\left(I_{g}-I_{c r}^{h}\right)\left(\frac{M_{c r}^{L}}{M_{a}}\right)^{3} & M_{c r}^{L}<M_{a} \leq M_{c d} \\ I_{c r}^{h}+\left(I_{g}-I_{c r}^{h}\right)\left(\frac{M_{c r}^{L}}{M_{a}}\right)^{3}-\beta_{s h}\left(\frac{M_{a}}{M_{c r}^{L}}\right) & M_{a}>M_{c d}\end{cases}
$$

The parameter $\beta_{s h}$ takes into account the rate of the linear decrease in $I_{\text {eff }}^{h}$ with increasing the maximum applied moment. The minimum value of $I_{e f f}^{h}$ at failure is defined based on the ratio of $M_{v} / M_{n}$, where $M_{v}$ is the maximum moment corresponding to the nominal shear strength of the beam $\left(V_{n}\right)$, and it is calculated by $M_{v}=V_{n} \cdot a$. Hence, $I_{e f f}^{h}$ can be derived using 


$$
I_{e f f}^{h}\left(M_{a}=M_{v}\right)=\left(\frac{M_{v}}{M_{n}}\right) I_{c r}^{h} \quad \text { where } M_{v} \leq M_{n}
$$

when $M_{v}>M_{n}$, the minimum value of $I_{\text {eff }}^{h}$ at failure is equal to $I_{c r}^{h}$ from Eq. (33). The coefficient $\beta_{s h}$ can be obtained by substituting Eq. (37) into Eq. (36) for $M_{a}=M_{v}$ :

$$
\beta_{s h}=\left[\left(1-\frac{M_{v}}{M_{n}}\right) I_{c r}^{h}+\left(I_{g}-I_{c r}^{h}\right)\left(\frac{M_{c r}^{L}}{M_{v}}\right)^{3}\right]\left(\frac{M_{c r}^{L}}{M_{v}}\right)
$$

\subsection{Crack spacing}

Crack spacing can be calculated by using the value recommended by RILEM TC 162-TDF [25] for case of FRC beams reinforced by conventional steel bars, but, replacing the corresponding parameters in case of steel bars by those for FRP bars.

The proposed equation by RILEM for calculation of crack spacing, $S_{c r}$, becomes

$$
S_{c r}^{\mathrm{RILM}}=\left(50+0.25 k_{1} k_{2} \frac{A_{c, e f} \phi_{f}}{A_{f}}\right)\left(\frac{50}{l_{s f} / \phi_{s f}}\right)
$$

where $l_{s f}$ and $\phi_{s f}$ are the length and diameter of the used steel fibers, which was included in Table 2. The parameter $\phi_{f}$ is GFRP bar's diameter. Further, the coefficients $k_{1}$ and $k_{2}$ are the factors that take into account the bond quality, and the form of strain distribution respectively. Due to the good bond quality obtained between the utilized GFRP bars and FRC material in the previous study carried out by the authors [34], the recommendation in terms of crack width and crack spacing for FRC beams reinforced by steel bars may be effectively used for case of SFRSCC beams reinforced by GFRP bars. Based on the recommended values by RILEM TC 162-TDF, $k_{1}=0.8$ for having good bond quality, and $k_{2}=0.5$ for bending condition. Further, the parameter $A_{c, e f}$ represents the effective tension area of SFRSCC surrounding the GFRP bars in the cross-section, giving by [25]

$$
A_{c, e f}=2.5\left(d_{f}^{\prime}+0.5 \phi_{f}\right) b
$$

where $d_{f}^{\prime}$ is the SFRSCC cover thickness for GFRP bars. According to Eq. (39), the crack spacing of the tested beams is calculated as $S_{c r}^{\text {RILEM }}=97 \mathrm{~mm}$, with an exception of IB4 that is $S_{c r}^{\text {RLEM }}=77 \mathrm{~mm}$ due to the higher number of GFRP bars installed in the cross-section. The calculated value of crack spacing 
will be compared with the value measured form the experimental crack pattern in section 4 .

\subsection{Theoretical crack width}

In the lack of formulation in the available design codes for calculation of crack width in case of the proposed hybrid reinforced SFRSCC beam, the recommendation proposed by ACI440-1R-06 [7] in case of FRP-RC beams as well as by RILEM TC 162-TDF [25] and CEB-FIB Model Code 2010 [24] for case of steel reinforced FRC beams are checked if they fit the case of the hybrid SFRSCC beams. For the last two design guidelines, the parameters corresponding to steel bars are replaced by the corresponding values for FRP bars.

ACI 440-1R-06 [7], guideline for design of FRP-RC elements, recommends the following equation for evaluating the crack width:

$$
w_{f}=2 \frac{f_{f}}{E_{f}} \beta k_{b} \sqrt{d_{f}^{\prime 2}+\left(\frac{s}{2}\right)^{2}}
$$

where $d_{f}^{\prime}$ and $s$ are FRP bar's concrete cover and spacing, respectively. Further, the parameter $\beta$ is defined as the ratio of distance between neutral axis and tension face to distance between neutral axis and centroid of reinforcement. The factor $k_{b}$ takes into account the degree of bond between FRP bars and surrounding concrete. According to ACI440-1R-06, the value of $k_{b}$ is ranged from 0.6 to 1.7 depending on the bond degree.

RILEM TC 162-TDF suggests that the crack width can be estimated by multiplying the average value of tensile strain of the reinforcing bars by the crack spacing. Though, the recommendation is for case of FRC beams reinforced by conventional steel bars, the same strategy may be relevant for case of the present study, replacing the corresponding parameters of steel bars by those from GFRP bars. Hence, the crack width becomes:

$$
w_{f}=k_{3} \bar{\varepsilon}_{f} S_{c r}^{\text {RILEM }}
$$

where $k_{3}$ is a coefficient relating the average crack width to the design value, which is set unit value to compare with the measured crack width from the tests. The parameter $\bar{\varepsilon}_{f}$ is the mean value of GFRP bar's stain over the crack spacing, given by 


$$
\bar{\varepsilon}_{f}=\frac{f_{f}}{E_{f}}\left[1-k_{4} k_{5}\left(\frac{\sigma_{s r}}{f_{f}}\right)^{2}\right]
$$

where the factors $k_{4}$ and $k_{5}$ take into account, respectively, the bond degree and the duration of the loading or of repeated loading, which both equal to one for case of this study [25].

More recently CEB-FIB Model Code 2010 proposed the following equation to determine the crack width for steel FRC members, which is verified in this study for case of the hybrid reinforced SFRSCC:

$$
w_{f}=2\left\{k \cdot d_{f}^{\prime}+\frac{1}{4} \frac{\left(f_{c t}-f_{F t s}\right)}{\tau_{b m}} \frac{A_{c, e f} \phi_{f}}{A_{f}}\right\} \frac{1}{E_{f}}\left(f_{f}-k_{6} \sigma_{s r}\right)
$$

Where $\tau_{b m}$ is bond shear strength, and $k_{6}$ is an empirical coefficient to assess the mean strain over the length which slip between concrete and reinforcing bar occurs, depending on the type of loading. $k_{6}=0.6$ is adopted for case of the present study [24]. It should be noticed that the shrinkage contribution is ignored in calculation of crack width by Eq. (44). Furthermore, the term inside the curly bracket in Eq. (44) is defined as the length over which slip between concrete and longitudinal reinforcement occurs (CEB-FIB Model Code 2010). Hence, double this value can be somehow taken as the average crack spacing that is recommended by CEB-FIB Model Code 2010.

The value of $\sigma_{s r}$ in Eqs. (43) and (44) is the tensile stress of GFRP bars calculated on the basis of a cracked section under loading conditions causing first cracking. This value can be computed by using the following equation for the both equations:

$$
\sigma_{s r}=\frac{A_{c, e f}\left(f_{c t}-f_{F t s}\right)}{A_{f}}\left(1+n \cdot \frac{A_{f}}{A_{c, e f}}\right)
$$

where $f_{F t s}=0.45 f_{R, 1}$. The calculated value of $f_{F t s}$ (given in Table 3 ) is higher than $f_{c t}$, meaning that the parcel $\left(f_{c t}-f_{F t s}\right)$ in Eqs. (44) and (45) becomes negative. Hence, the stress of the GFRP bars at crack initiation (i.e. $\left.\sigma_{s r}\right)$, is not meant to be in tension. In case of the present study, the parcel $\left(f_{c t}-f_{F t s}\right)$ is assumed null, meaning that the value of $\sigma_{s r}$ is almost negligible. The obtained results of the crack width in terms of $w_{f}-f_{f}$ diagram will be compared with those obtained by the experiments in the next section. 


\section{Results and discussion}

\subsection{Flexural strength and failure mode of the tested beams}

The maximum experimental moment ( $M_{u, \exp }$ ) carried by the tested beams was calculated from the respective maximum load $\left(P_{\max }\right)$ that was registered during the monotonic tests, giving by

$$
M_{u, \exp }=\frac{1}{2} P_{\max } \cdot a
$$

where $a$ is the shear span. The calculated values of $M_{u \text { exp }}$ are reported in Table 7 for Group A and B of the beams. The theoretical moment that causes the yielding in steel strand can be obtained by using the output results from DOCROS software. This theoretical moment is nominated by $M_{y}$, and their values are included in Table 7 for the tested beams. By comparing between $M_{u \text {,exp }}$ and $M_{y}$, it can be stated that the steel strand reached the yielding stress for Group B of the beams (with an exception of IB5 as the none-prestressed beam), while no beam in Group A experienced the value of moment greater than $M_{y}$. For this reason, the failing of the beams in Group A is called "shear failure", while the failing of the prestressed IBs in Group B are all "flexo-shear failure" as indicated in Table 7. This was evidenced by means of the last measured strain by "SGst" installed on steel strand (shown in Figure 2), being $0.86 \%$ for IB6, and $1.06 \%$ for IB8, corresponding to $27.5 \mathrm{~mm}$ and $22 \mathrm{~mm}$ of mid span deflection, respectively. Since the beams experienced higher applied moment after this point, and also the strain gauges on GFRP bars kept increasing at mid-span, it can be concluded that the steel has already yielded at failure. Unfortunately, "SGst" for IB10 was failed at the beginning of the test. It should be noticed that, it was unlikely to have this type of strain gauge working beyond the strain of about $1 \%$ (i.e. $\varepsilon_{s}>1 \%$ ) .

Additionally, the ultimate crack pattern and the failure mode of the tested beams are illustrated in Figure 7 for Group A, and in Figure 8 for Group B. As shown in these two figures, all the beams failed at the ultimate stage, by propagation of diagonal cracks in the shear spans starting from the bottom flange toward the loading point, with the exception of IB4 (over-reinforced condition, see Table 6). IB4 was failed by progressing a shear crack from the loading point through the junction plane between the 
bottom flange and web plate for the maximum applied moment less than the value registered for IB3 beam. The premature rupture of the IB4 beam is mainly caused by the increase of the flexural reinforcement, since this increases the stiffness of the bottom flange of the beam, as well as the dowel effect. These two factors contribute for the higher resistance of the flange zone to be crossed by a shear crack, which promotes its propagation at the interface between bottom web and flange. Since this interface has no stirrups resisting to these in-plane shear stresses, and the percentage of fibers giving effective contribution for shear resistance is relatively small (the fibers have the tendency to get a horizontal direction [35]), a premature failure occurred in this beam.

The nominal flexural strength $\left(M_{n}\right)$ from the theoretical methods described in section 3.2 are included in Table 7. No significant change was observed in the ratio of $M_{u, \exp } / M_{n}$ for the tested beams in Group A (with an exception of IB4 that had a premature failure), meaning that by increasing the prestress level of the over-reinforced beams, no significant increase is attained in flexural strength of the beam. However, this ratio significantly increased by increasing the prestress level of the underreinforced beams in Group B in which the flexural strength reached about $93 \%$ of its nominal value for IB10 (with 40\% of prestress level in GFRP bars).

\subsection{Force-deflection relationship}

\subsubsection{Effective moment of inertia}

The experimental effective moment of inertia of the tested beams (i.e. $I_{\text {eff }}^{\text {exp }}$ ) can be calculated using

$$
I_{e f f}^{\exp }=\frac{\left(\frac{3}{4} S^{2}-a^{2}\right)}{6 E_{c}} \frac{M_{a}}{D_{\max }}
$$

where $M_{a} / D_{\max }$ is taken from the test results at beam's mid-span section. The calculated results are plotted in Figure 9a for Group A, and in Figure 9b for Group B. This figure shows that the flexural stiffness of the beams has increased with the applied prestress level. Although the tested beams in Group B showed different load carrying capacities, the ultimate $I_{\text {eff }}^{\text {exp }}$ at failure was almost same for all the beams in this group (see the graph with higher magnification in Figure 9b). This means that the ultimate $I_{\text {eff }}^{\text {exp }}$ is not influenced by the level of prestress in the reinforcements. In fact, increasing the prestress 
level of the reinforcements only the cracking moment increases, which delays the beam to reach the ultimate $I_{\text {eff }}^{\exp }$.

Additionally, the values obtained from Eq. (36) previously proposed to evaluate the effective moment of inertia of hybrid SFRSCC beams (i.e. $I_{\text {eff }}^{h}$ ) are plotted in Figure 9. As shown, the proposed equation can predict with acceptable accuracy the experimental results in terms of $I_{\text {eff }}-M_{a}$. The coefficient $\beta_{s h}$ was defined to consider the effect of shear crack propagation on the effective moment of inertia. In order to show the influence of this factor, the experimental $I_{\text {eff }}-M_{a}$ of IB6 (as example), is compared with the respective theoretical results by Eq. (26) for $\beta_{s h}=0$, and for $\beta_{s h}$ by Eq. (38) in Figure 10. When $\beta_{s h}$ is null, the experimental results in terms of $I_{\text {eff }}-M_{a}$ are overestimated; however, the experimental relationship is well captured when $\beta_{s h}$ is obtained from Eq. (38).

\subsubsection{Force-deflection up to service load}

The force-deflection relationship of the tested beams is plotted in Figure 11 up to the deflection of $15 \mathrm{~mm}$, which is about $L / 250$ that is typically defined as the deflection limit for service conditions (ACI318-08 [36]). The increase in the service load by increasing the prestress level is observable from this figure. In addition to the experimental results, the force-deflection relationship from the DefDOCROS software, and by Eq. (25) for $I_{g}=I_{\text {eff }}^{h}$, which is designated as "direct method", are also shown in this figure. It should be noticed that when theoretical deflection is calculated by using the

proposed effective moment of inertia, $I_{\text {eff }}^{h}$, from Eq. (36), the value of $M_{v}$ in Eq. (37) was taken as the ultimate moment obtained from the experiments $\left(M_{u, \exp }\right)$. Up to the service load (or service moment, $M_{S L S}$ included in Table 7), corresponding to a deflection of about $9 \mathrm{~mm}$, the accuracy of both theoretical approaches to predict the crack initiation is acceptable. As already referred, the limit of proportionality $\left(f_{c t, L}\right)$ should be used to estimate the effective crack initiation response of SFRSCC prestressed beams.

For mid span deflection between 9 and $15 \mathrm{~mm}$, the accuracy of both theoretical approaches to predict the results in Group B was acceptable. However, for Group A, the Def-DOCROS overestimated 
the experimental results, while the direct method has provided accurate predictions (except IB1). This is mainly due to the different distance of loading point loads adopted for the tests of the beams of Groups A and B (750 mm and $500 \mathrm{~mm}$ for Group A and Group B, respectively). Due to the lower shear span in Group A, the effect on the beam curvature due to the propagation of shear cracks was initiated at a lower value of deflection at mid span. Therefore, the results from Def-DOCROS, which did not consider this effect, overestimated the experimental load carrying capacity for mid span deflection higher than about $9 \mathrm{~mm}$.

Contrary to the other beams of Group A, in the IB1 beam the Def-DOCROS has predicted more accurately the experimental force-deflection relationship than the direct method. This may be due to asymmetrical distribution of the load applied to the two point loads during the test in IB1 beam. This non-uniform response is more visible in the total force-deflection relationship of IB1, as it is shown in next section.

\subsubsection{Total force-deflection relationship}

The total force-deflection relationship up to the failure of the beams of Group A and B are plotted in Figure 12 and Figure 13, respectively. In addition to the experimental results, the force-deflection relationship from the Def-DOCROS software, and the results obtained by Eq. (25) with $I_{g}=I_{\text {eff }}^{h}$, which is designated by "direct method", are shown in these figures. The direct method, which is based on the proposed effective moment of inertia by Eq. (36) for hybrid systems, estimates with acceptable accuracy the force-deflection relationship of the beams up to the ultimate stage. However, the Def-DOCROS overestimates the load carrying capacity registered experimentally (in fact it is the deflection that is underestimated) because this numerical model does not implement in the stiffness matrix of the adopted displacement method, the shear stiffness degradation occurred during the loading process [31].

The experimental force-deflection relationship recorded in IB1 showed abnormal behavior comparing to the other beams of Group A. A great load decay was observed in the recorded forcedeflection relationship at about $32 \mathrm{~mm}$ mid span deflection (see Figure 12, IB1). The reason of this abnormal behavior may be due to non-uniform distribution of the load applied in the two point loads. In this test, a critical diagonal crack was formed firstly at one side of the beam's shear span, which resulted 
in the first load decay. Afterward, the applied load started increasing again, leading to the formation of another critical diagonal crack in the other beam's shear span, which resulted in the second load decay, followed immediately by the failure of the beam. This non-uniform behavior can be mainly due to a deficient casting process of the SFRSCC and/or a quite different fiber distribution and orientation between the shear spans. Therefore, the cross sections in the two shear span have different flexural stiffness, mainly after crack initiation, which justify this abnormal behavior of the whole system.

The theoretical "yielding point" that is defined by $M_{y}$ and its corresponding mid span deflection $\left(D_{y}\right)$ at yield initiation of the steel strand, are also indicated in Figure 12 and Figure 13 for all tested beams. Note that $D_{y}$ was obtained as the output results from Def-DOCROS software, whose values are included in Table 7. As already mentioned, none of the beams in Group A has attained $M_{y}$. Conversely, the maximum applied moment for the prestressed beams in Group B was higher than $M_{y}$ , meaning that steel strand yielded for this group of specimens. This provided higher ductility to the beams of Group B, as it is discussed in the next section.

\subsection{Ductility and deformability}

Deformability is an important aspect for determining the safety of FRP prestressed beams. Since FRP bars are brittle materials, a care should be taken to ensure sufficient warning for these type of structures. Based on the deformability-approach firstly proposed by [37], ductility of FRP-RC members can be measured taking into account the "strength effect" and "deformation effect":

$$
\mu=C_{s} \times C_{d}
$$

with the following definition:

$$
C_{s}=\frac{M_{u}}{M_{S L S}}, C_{d}=\frac{D_{u}}{S / 250}
$$

where $M_{S L S}$ is the applied moment corresponding to SLS for mid-span deflection being equal to $L / 250$ (see Table 7), and $M_{u}$ is the maximum moment that carried by the beam at ultimate limit stage. Also, $D_{u}$ is the maximum deflection that corresponds to the peak load in the force-deflection relationship. The ductility index $(\mu)$ is defined by multiplying these two factors. The calculated ductility 
index, as well as the strength and deformation effects of the tested beams are compared using three column charts presented in Figure 14a, b and c. To better understand the ductility improvements of the tested beams, the deformation and strength effects calculated by using the force-deflection relationship obtained from the Def-DOCROS software are also presented in these figures. The reason of this comparison is that Def-DOCROS was developed for simulating the behavior of elements failing in bending. Hereafter, the force-deflection relationship of the I-beams from Def-DOCROS, which is only governed by flexural deformation of the beam, is known as "reference response".

\subsubsection{Strength effect}

From Figure 14a, the strength effect, $C_{s}$, calculated from the experimental force-deflection relationship are totally lower than the respective value calculated from the "reference response". By increasing the prestress level of the beam, the difference between these two values becomes smaller in which for IB10 with the highest amount of prestress level the difference is almost negligible.

\subsubsection{Deformation effect}

In Figure 14b, the deformation effect, $C_{d}$, that is calculated from experimental force-deflection relationship are compared with those obtained from the "reference response". With an exception of the non-prestressed I-beams, $C_{d}$ increases for all the prestressed I-beams. This increase is much higher for the case of under-reinforced beams in Group B, in which the value of $C_{d}$ from the experiments is about two times higher than the calculated $C_{d}$ from the "reference response".

\subsubsection{Ductility index}

The ductility index, $\mu$, of the tested beams is compared with the ones obtained from the "reference response". As shown in Figure 14c, the ductility corresponding to elements governed by flexural deformation was not attained in over-reinforced beams (Series A), while it was exceeded in the underreinforced beams (Series B). In fact, the prestressed IB6, IB8 and IB10 can exhibit enough deformation at the ultimate stage before failing with no loss of the strength. This can be a great achievement in terms of structural performance of the proposed hybrid SFRSCC prestressed beams, in which the beams behaves efficiently similar to its "reference response" up to the service loads, afterward, at ultimate limit stage, the progressive degradation of beam curvature in the flexure-shear region introduces higher 
deformation to the global response of the beam, while the beam that can maintain the flexural strength.

\subsection{Cracking behavior}

\subsubsection{Crack pattern}

A comparison between the crack patterns of IB5, IB6 and IB8 for mid-span deflection of about $15 \mathrm{~mm}$ are given in Figure 15. The cracking length of the tested beams decreases (from 1740 to $1440 \mathrm{~mm}$ ) with an increase in the prestress force of the reinforcements at the same level of deflection at mid-span. The cracking length is simply defined by the length of beam span that is no longer in the elastic phase, and it may be experimentally approximated by the distance between the last two formed cracked at two sides of the beam, as shown in Figure 15. The decrease in the cracking length is due to the fact that the prestress level of reinforcing bars increases the cracking moment of the beam because of the initial confinement and negative camber that imposes to the beam. The prestress level of the longitudinal reinforcements showed no significant effect on crack spacing of the beams. The average experimental crack spacing, $S_{c r}^{\text {exp }}$, obtained measured from the tested IB5, IB6, and IB8 is written in Figure 15. The measured crack spacing is in good agreement with the crack spacing recommended by RILEM in Eq. (39). Additionally, the theoretical level of the neutral axis obtained by DOCROS at SLS is illustrated in Figure 15 using a bold dashed-line. The position of crack tips in the constant moment region can approximately represent the experimental level of natural axis in this region.

\subsubsection{Crack width}

The value of maximum crack with versus the average tensile stress of GFRP bars in pure bending zone measured by the installed strain gauges (SG2, SG3 and SG4) are plotted in Figure 16 for IB5, IB6, IB8 and IB10. The experimental crack width was measured by using a microscope device with $1 / 20 \mathrm{~mm}$ of measuring precision for different level of applied moment less than $M_{S L S}$ (written in Table 7). In addition to the experimental measurements, the theoretical curves obtained by Eq. (41) given by ACI 440-1R-06[7] is plotted in Figure 16. As shown, depending on the given value to the parameter $k_{b}$, a wide range of crack width values is obtained for FRP-RC tested. The highest accuracy belongs to the curve that is obtained for $k_{b}=0.6$, which represents the highest bond degree between GFRP bars and SFRSCC. Additionally, Eq. (42) recommended by RILEM in case of steel-FRC beams, predicts with an 
acceptable accuracy the experimental results of crack width. In this equation, the bond quality between GFRP and SFRSCC was also taken as the highest value by giving 1.0 to the parameter $k_{3}$. On the other hand, the theoretical crack width recommended by CEB-FIB Model Code 2010, from Eq. (44), underestimated the measured crack width during the tests.

\section{Conclusion}

In the present work the deflection and cracking behavior of I-shaped cross-sectional beams of SFRSCC reinforced in flexure with hybrid prestressed steel strand and glass fiber reinforced polymer (GFRP) bars was investigated. Based on the results of the experimental study and theoretical investigation presented and developed in this paper, the following conclusions can be remarked:

i. A new concept for balanced reinforcement ratio of hybrid FRP-steel FRC beam was proposed in this study. When the FRP reinforcement ratio was lower than this balanced reinforcement ratio, the increase in the prestress level in the reinforcement improve clearly the structural performance of the hybrid system, however, it showed no significant contribution when the beams were over reinforced. This new balanced reinforcement ratio can be used as design criterion to address the behavior of the reinforced hybrid beam at ultimate limit stage.

ii. A significant improvement in terms of deformability was achieved for under reinforced prestressed hybrid FRC beam with no significant loss in flexural strength of the beam. This results in noticeable increase in ductility index (more than two times) for prestressed beam with 30 and $40 \%$ prestress in GFRP bars;

iii. When the bond quality of the reinforcing bars and concrete was considered as the highest degree, design crack width value given by RILEM (which is recommended for FRC material reinforced by conventional steel bars), and by ACI (which is recommended for FRP-RC beams) approximated well CMOD measured from the tests.

iv. The proposed method to predict the force-deflection response of the hybrid prestressed beam, which is based on a new definition of the effective moment of inertia, $I_{\text {eff }}$, predicts with an acceptable accuracy the experimental force-deflection. The proposed effective moment of inertia takes into account the effect of prestress in the reinforcements, the increase in curvature 
of the beam due to shear crack propagation, and the stiffening effect due to steel fibers at crack initiation. 


\section{ACKNOWLEDGEMENTS}

The first acknowledges the $\mathrm{PhD}$ grant SFRH/BD/77409/2011 provided by FCT (Fundação para a Ciência e a Tecnologia), while the third author acknowledges the research grant in the ambit of the project DURCOST - Innovation in reinforcing systems for sustainable pre-fabricated structures of higher durability and enhanced structural performance, PTDC/ECM/105700/2008. The research carried out in this paper was supported by DURCOST. The authors also thank the collaboration of the following companies: Sireg and Schoeck for providing the GFRP rebars, Casais to manufacture the moulds, Ibermetais for supplying the steel fibres, Secil/Unibetão for providing the Cement, and BASF for supplying the superplasticizer. 


\section{References}

[1] Barris, C., Torres, L., Turon, A., Baena, M., and Catalan, A., An experimental study of the flexural behaviour of GFRP RC beams and comparison with prediction models. Composite Structures, 2009. 91(3): p. 286-295.

[2] Tavares, D. H., Giongo, J. S., and Paultre, P., Behavior of reinforced concrete beams reinforced with GFRP bars. RIEM-Revista IBRACON de Estruturas e Materiais, 2008. 1(3).

[3] Rasheed, H. A., Nayal, R., and Melhem, H., Response prediction of concrete beams reinforced with FRP bars. Composite Structures, 2004. 65(2): p. 193-204.

[4] Toutanji, H. and Deng, Y., Deflection and crack-width prediction of concrete beams reinforced with glass FRP rods. Construction and Building Materials, 2003. 17(1): p. 69-74.

[5] Abdalla, H., Evaluation of deflection in concrete members reinforced with fibre reinforced polymer (FRP) bars. Composite Structures, 2002. 56(1): p. 63-71.

[6] Aiello, M. and Ombres, L., Cracking analysis of FRP-reinforced concrete flexural members. Mechanics of composite materials, 2000. 36(5): p. 389-394.

[7] ACI Committee 440, Guide for the design and construction of structural concrete reinforced with FRP bars (ACI 440.1R-06). 2006: American Concrete Institute, Farmington Hills, MI, USA.

[8] Canadian Standard Association (CSA), Design and construction of building component with fiberreinforced polymers. 2002: CSA Standard S806-02, Toronto, Cananda.

[9] Japan Society of Civil Engineers (JSCE), Recommandation for design and construction of concrete structure using continous fiber reinforcing materials. 1997: N23, Concrete engineering series, Japan.

[10] Choi, D.-U., Chun, S.-C., and Ha, S.-S., Bond strength of glass fibre-reinforced polymer bars in unconfined concrete. Engineering Structures, 2012. 34: p. 303-313.

[11] Harajli, M. and Abouniaj, M., Bond performance of GFRP bars in tension: Experimental evaluation and assessment of ACI 440 guidelines. Journal of Composites for Construction, 2010. 14(6): p. 659-668.

[12] Harris, H. G., Somboonsong, W., and Ko, F. K., New ductile hybrid FRP reinforcing bar for concrete structures. Journal of Composites for Construction, 1998. 2(1): p. 28-37.

[13] Barros, J. and Sena Cruz, J., Fracture energy of steel fiber-reinforced concrete. Mechanics of Composite Materials and Structures, 2001. 8(1): p. 29-45.

[14] Yang, J.-M., Min, K.-H., Shin, H.-O., and Yoon, Y.-S., Effect of steel and synthetic fibers on flexural behavior of high-strength concrete beams reinforced with FRP bars. Composites Part B: Engineering, 2012. 43(3): p. 1077-1086.

[15] Wang, H. and Belarbi, A., Ductility characteristics of fiber-reinforced-concrete beams reinforced with FRP rebars. Construction and Building Materials, 2011. 25(5): p. 2391-2401.

[16] Issa, M. S., Metwally, I. M., and Elzeiny, S. M., Influence of fibers on flexural behavior and ductility of concrete beams reinforced with GFRP rebars. Engineering Structures, 2011. 33(5): p. 1754-1763.

[17] Alsayed, S. H. and Alhozaimy, A. M., Ductility of concrete beams reinforced with FRP bars and steel fibers. Journal of composite materials, 1999. 33(19): p. 1792-1806.

[18] Soltanzadeh, F., Behbahani, A. E., Mazaheripour, H., and Barros, J. A., Shear Resistance of SFRSCC Short-Span Beams without Transversal Reinforcements. Composite Structures, 2015.

[19] Lau, D. and Pam, H. J., Experimental study of hybrid FRP reinforced concrete beams. Engineering Structures, 2010. 32(12): p. 3857-3865.

[20] Qu, W., Zhang, X., and Huang, H., Flexural Behavior of Concrete Beams Reinforced with Hybrid (GFRP and Steel) Bars. Journal of Composites for Construction, 2009. 13(5): p. 350-359.

[21] Leung, H. and Balendran, R., Flexural behaviour of concrete beams internally reinforced with GFRP rods and steel rebars. Structural Survey, 2003. 21(4): p. 146-157.

[22] Aiello, M. A. and Ombres, L., Structural performances of concrete beams with hybrid (fiberreinforced polymer-steel) reinforcements. Journal of Composites for Construction, 2002. 6(2): p. 133-140.

[23] Soltanzadeh, F., Barros, J. A. O., and Santos, R. F. C., High performance fiber reinforced concrete for the shear reinforcement: Experimental and numerical research. Construction and Building Materials, 2015. 77: p. 94-109. 
[24] CEB-FIB, Model Code 2010 - Final draft. 2010: Thomas Thelford, Lausanne, Switzerland.

[25] RILEM TC162-TDF, Test and design methods for steel fibre reinforced concrete: Bending test, in Materials \& Structures. 2000. p. 3-5.

[26] Cunha, V. M. C. F., Steel Fibre Reinforced Self-Compacting Concrete (from Micro-Mechanics to Composite Behaviour). 2010, Guimaraes, Portugal: University of Minho.

[27] Varma, R. K., Numerical models for the simulation of the cyclic behaviour of RC structures incorporating new advanced materials. 2013, PhD thesis, University of Minho: Guimaraes, Portugal.

[28] Barros, J. A., Oliveira, J. T., Bonaldo, E., and Lourenco, P. B., Flexural behavior of reinforced masonry panels. American Concrete Institute (ACI), 2006. 103(3): p. 418-26.

[29] Taheri, M., Barros, J. A. O., and Salehian, H., A design model for strain-softening and strainhardening fiber reinforced elements reinforced longitudinally with steel and FRP bars. Composites Part B: engineering, 2011. 42(6): p. 1630-1640.

[30] Barros, J. A., Varma, R. K., Sena-Cruz, J. M., and Azevedo, A. F., Near surface mounted CFRP strips for the flexural strengthening of RC columns: Experimental and numerical research. Engineering Structures, 2008. 30(12): p. 3412-3425.

[31] Barros, J. A. and Fortes, A., Flexural strengthening of concrete beams with CFRP laminates bonded into slits. Cement and Concrete Composites, 2005. 27(4): p. 471-480.

[32] ACI Committee 440, Prestressing Concrete Structures with FRP Tendons (ACI 440.4R-04). 2004: American Concrete Institute, Farmington Hills, MI, USA.

[33] Cunha, V. M., Barros, J. A., and Sena-Cruz, J. M., Pullout behavior of steel fibers in selfcompacting concrete. Journal of Materials in Civil Engineering, 2010. 22(1): p. 1-9.

[34] Mazaheripour, H., Barros, J. A. O., Sena Cruz, J. M., Pepe, M., and Martinelli, E., Experimental study on bond performance of GFRP bars in self-compacting steel fiber reinforced concrete. Composite Structures, 2013. 95: p. 202-212.

[35] Abrishambaf, A., Barros, J. A. O., and Cunha, V. M. C. F., Relation between fibre distribution and post-cracking behaviour in steel fibre reinforced self-compacting concrete panels. Cement and Concrete Research, 2013. 51: p. 57-66.

[36] ACI Committee 318, Building Code Requirments for Reinforced Concrete (ACI 318-08). 2008: American Concrete Institute, Farmington Hills, MI, USA. p. 353.

[37] Jaejer, L., Mufti, A., and Tadros, G. The concept of the overall performance factor in rectangularsection reinforced concrete beams. in Proceedings of the 3rd International Symposium on NonMetallic (FRP) Reinforcement for Concrete Structures. 1997. 


\begin{tabular}{|c|c|c|c|}
\hline \multicolumn{4}{|c|}{ Notations } \\
\hline$a$ & shear span of beam & $f_{c}^{\prime}$ & the concrete compressive strength \\
\hline$A_{c t, b}$ & $\begin{array}{l}\text { tensile area of beam's cross section under leve } \\
\text { of neutral axis at balanced condition }\end{array}$ & $f_{c t}$ & SFRSCC tensile strength \\
\hline$A_{f}$ & area of GFRP bar's cross section & $f_{c t, L}$ & $\begin{array}{l}\text { limit of proportionality calculated for CMOD } \\
=0.05 \mathrm{~mm} \text { in standard notched beam test }\end{array}$ \\
\hline$A_{g}$ & gross area of SFRSCC beam's cross section & $f_{f}^{\text {pre }}$ & prestress of GFRP bar \\
\hline$A_{s}$ & area of steel strand's cross section & $f_{f u}$ & the ultimate tensile stress of GFRP bars \\
\hline$b$ & $\begin{array}{l}\text { width of bottom flange in SFRSCC beam's } \\
\text { cross section }\end{array}$ & $f_{F t s}$ & $\begin{array}{l}\text { the residual flexural stress of SFRSCC defined } \\
\text { by Model Code } 2010\end{array}$ \\
\hline$b_{n}$ & $\begin{array}{l}\text { width of beam in the notched beam bending } \\
\text { tests }\end{array}$ & $f_{F t u}$ & $\begin{array}{l}\text { the residual flexural stress of SFRSCC defined } \\
\text { by Model Code } 2010\end{array}$ \\
\hline$b_{w}$ & width of web in SFRSCC beam's cross section & $f_{R, j}$ & $\begin{array}{l}\text { the residual flexural stresses of SFRSCC defined } \\
\text { by Model Code } 2010(j=1,2,3,4)\end{array}$ \\
\hline$c$ & the depth of neutral axis & $f_{s}^{\text {pre }}$ & prestress of steel strand \\
\hline$c_{b}$ & $\begin{array}{l}\text { the depth of neutral axis at the balanced } \\
\text { section condition }\end{array}$ & $f_{s u}$ & the ultimate tensile stress of steel strand \\
\hline$c_{v}$ & $\begin{array}{l}\text { the depth of neutral axis in a flexure-shear } \\
\text { crack in shear span }\end{array}$ & $f_{s y}$ & yielding stress of steel strand \\
\hline$C_{d}$ & $\begin{array}{l}\text { the strength effect in calculation of ductility } \\
\text { index }\end{array}$ & $F_{c}$ & $\begin{array}{l}\text { the resultant of compressive force at cracked } \\
\text { SFRSCC beam's cross section }\end{array}$ \\
\hline$C_{s}$ & $\begin{array}{l}\text { the deformation effect in calculation of } \\
\text { ductility index }\end{array}$ & $F_{c, b}$ & $\begin{array}{l}\text { the resultant of compressive force at balanced } \\
\text { cracked SFRSCC beam's cross section }\end{array}$ \\
\hline$d_{f}$ & $\begin{array}{l}\text { the arm of tensile force of GFRP bars at } \\
\text { SFRSCC beam's cross section }\end{array}$ & $F_{f, b}$ & $\begin{array}{l}\text { the tensile force of GFRP bars at balanced } \\
\text { cracked SFRSCC beam's cross section }\end{array}$ \\
\hline$d_{f}^{\prime}$ & $\begin{array}{l}\text { SFRSCC concrete cover of GFRP bars } \\
\text { (measured from bottom surface of section) }\end{array}$ & $F_{j}$ & $\begin{array}{l}\text { the applied force in notched beam test } \\
\text { corresponding to } f_{R, j}\end{array}$ \\
\hline$d_{f, e q}$ & $\begin{array}{l}\text { the arm of tensile force of equivalent GFRP } \\
\text { bars at SFRSCC beam's cross section }\end{array}$ & $F_{f}$ & $\begin{array}{l}\text { the tensile force of GFRP bars at cracked } \\
\text { SFRSCC beam's cross section }\end{array}$ \\
\hline$d_{f r}$ & $\begin{array}{l}\text { the arm of the resultant of the residual tensile } \\
\text { force by fibers at beam's cross section }\end{array}$ & $F_{f r}$ & $\begin{array}{l}\text { the resultant of tensile force at cracked SFRSCC } \\
\text { beam's cross section (due to fibers) }\end{array}$ \\
\hline$d_{s}$ & $\begin{array}{l}\text { the arm of tensile force of steel strand at } \\
\text { SFRSCC beam's cross section }\end{array}$ & $F_{f r, b}$ & $\begin{array}{l}\text { the resultant of tensile force at balanced cracked } \\
\text { FRC beam's cross section by fibers }\end{array}$ \\
\hline$D_{m i d}$ & mid span deflection of tested beams & $F_{s}$ & $\begin{array}{l}\text { the tensile force of steel strand bars at cracked } \\
\text { SFRSCC beam's cross section }\end{array}$ \\
\hline$D_{y}$ & $\begin{array}{l}\text { mid span deflection corresponding to yielding } \\
\text { of steel strand }\end{array}$ & $F_{s y}$ & yielding force of steel strand \\
\hline$E_{c}$ & Young's modulus of SFRSCC material & $h$ & height of I shaped SFRSCC beam's cross section \\
\hline$E_{f}$ & Young's modulus of GFRP bar & $h_{1}$ & $\begin{array}{l}\text { height of the flanges in I shaped SFRSCC } \\
\text { beam's cross section }\end{array}$ \\
\hline$E_{s}$ & Young's modulus of steel strand & $h_{2}$ & $\begin{array}{l}\text { height of the flanges in I shaped SFRSCC } \\
\text { beam's cross section }\end{array}$ \\
\hline
\end{tabular}




\section{Notations}

$h_{3}$ height of the web in I shaped SFRSCC beam's $M_{c d}$ the moment corresponding to $V_{c d}$ cross section

$h_{s p} \quad$ height of the notched section in the standard notched beam benign test

$M_{c r}^{L} \quad$ the cracking moment of I shaped SFRSCC beam the moment of inertia of cracked FRP-RC beam's cross section

$I_{c r}^{h} \quad$ the moment of inertia of cracked hybrid FRP/steel SFRSCC beam's cross section

$I_{e f f}$ the effective moment of inertia of FRP-RC beam

$M_{n} \quad$ the nominal flexural strength of beam

$M_{p} \quad$ moment due to the eccentrically applied prestress force

$M_{S L S}$ the applied moment corresponding to $L / 250$

$I_{e f f, \exp }^{h}$ The experimental effective moment of inertia of hybrid GFRP/steel SFRSCC beam

$M_{u} \quad$ the peak applied moment in moment-deflection relationship of beam

$I_{e f f}^{h} \quad$ the effective moment of inertia of hybrid GFRP/steel SFRSCC beam

$M_{u, \exp }$ the peak applied moment in moment-deflection $u$,exp relationship of the tested beams

$M_{v} \quad$ the moment corresponding to $V_{n}$ GFRP/steel SFRSCC beam

$k \quad$ the factor in calculation of nominal shear strength of beam by

Eq. Error! Reference source not found.

$k_{1} \quad$ the factors that take into account the bond quality (Eq. (39))

$k_{2} \quad$ the factors that take into account the form of strain distribution (Eq. (39))

$k_{3} \quad$ factors taking into account the bond quality (Eq. (42))

$M_{y} \quad$ the applied moment corresponding to yield initiation of steel strand

$n_{r} \quad$ the ratio between the Young's modulus of steel strand and GFRP bar

$n_{f} \quad$ the ratio between the Young's modulus of GFRP

bar and SFRSCC

$N_{f p} \quad$ axil prestressed force applied to beam due to GFRP bars

$k_{4} \quad$ factors taking into account the duration of the loading or of repeated loading (Eq. (52))

$N_{s p}$

axil prestressed force applied to beam due to steel strand

$k_{b} \quad$ the factors that take into account the bond quality (Eq. (50))

$P_{\max } \quad$ the peak applied force in force-deflection relationship of the tested beams

$l \quad$ span of the standard notched beam test

$P_{s} \quad$ the maximum tensile force transferred due to bond behavior of the steel strand

$l_{c s} \quad$ characteristic length defined by Model Code $s$ 2010

horizontal distance between GFRP bars at beam's cross section

$L \quad$ span of the I shaped hybrid SFRSCC prestressed beam

$S_{c r} \quad$ crack spacing

$m_{f r} \quad$ factor to calculate balanced reinforcement ratio $S_{c r}^{\text {RILEM }}$ by Eq.

$m_{1} \quad$ modified factor to calculate the depth of $\quad V$ neutral axis by Eq. (16)

$V \quad$ the applied shear force in shear span of beam

$m_{2}$ modified factor to calculate the depth of neutral axis by Eq. (16)

$V_{c d} \quad$ the shear resistance of beam due to only concrete

$m_{s} \quad$ factor to calculate balanced reinforcement ratio $V_{n}$ by Eq. (4)

the nominal shear strength of hybrid reinforced SFRSCC prestressed beam

$M_{a} \quad$ the maximum applied moment carried by I $\quad w$ shaped SFRSCC beam at each level of loading

$M_{c r} \quad$ the cracking moment of I shaped SFRSCC $\quad w_{f}$ crack width at cracked section

crack width at the level of GFRP bars at cracked section 


\begin{tabular}{|c|c|c|c|}
\hline \multicolumn{4}{|c|}{ Notations } \\
\hline$w_{k}$ & design crack width & $\varepsilon_{s}^{\text {pre }}$ & pre-strain of steel strand \\
\hline$\alpha_{1}$ & $\begin{array}{l}\text { the parameter define the rectangular SFRSCC } \\
\text { compressive stress block of at crack section }\end{array}$ & $\varepsilon_{s u}$ & breaking tensile strain of steel strand \\
\hline$\beta$ & $\begin{array}{l}\text { coefficient relating the average crack width to } \\
\text { the design value }\end{array}$ & $\mu$ & ductility index of beam \\
\hline$\beta_{1}$ & $\begin{array}{l}\text { the parameter define the rectangular SFRSCC } \\
\text { compressive stress block of at crack section }\end{array}$ & $\rho_{c}$ & defined by Eq. (9) \\
\hline$\beta_{2}$ & $\begin{array}{l}\text { parameter that takes into account the particular } \\
\text { geometry of the adopted I shape cross section }\end{array}$ & $\rho_{f}$ & GFRP reinforcement ratio \\
\hline$\beta_{d}$ & $\begin{array}{l}\text { factor that takes into account the relatively } \\
\text { smaller tension stiffening effect of FRP bars }\end{array}$ & $\varepsilon_{s y}$ & yielding strain of steel strand \\
\hline$\beta_{s h}$ & $\begin{array}{l}\text { factor that takes into account the crack shear } \\
\text { propagation in the proposed direct method }\end{array}$ & $\rho_{f b}$ & FRP balanced reinforcement ratio \\
\hline$\gamma$ & $\begin{array}{l}\text { factor to calculate the depth of neutral axis by } \\
\text { Eq. (16) }\end{array}$ & $\rho_{f, e q}$ & equivalent GFRP reinforcement ratio \\
\hline$\gamma_{c}$ & $\begin{array}{l}\text { safety factor in calculation of the nominal } \\
\text { shear strength by }\end{array}$ & $\rho_{h b}$ & hybrid balanced reinforcement ratio \\
\hline$\varepsilon_{c}$ & $\begin{array}{l}\text { Eq. Error! Reference source not found. } \\
\text { SFRSCC compressive strain }\end{array}$ & $\rho_{s}$ & steel strand reinforcement ratio \\
\hline$\varepsilon_{c u}$ & Ultimate compressive strain in concrete & $\bar{\sigma}_{c t}^{c r}$ & $\begin{array}{l}\text { equivalent average value of crack tensile stress } \\
\text { of SFRSCC }\end{array}$ \\
\hline$\varepsilon_{c p}$ & $\begin{array}{l}\text { SFRSCC compressive strain at onset of its } \\
\text { plastic behavior }\end{array}$ & $\bar{\sigma}_{c t, b}^{c r}$ & $\begin{array}{l}\text { equivalent average value of crack tensile stress } \\
\text { of SFRSCC at balanced condition }\end{array}$ \\
\hline$\varepsilon_{c t}$ & SFRSCC tensile strain & $\sigma_{c}^{\text {pre }}$ & $\begin{array}{l}\text { average compressive stress acting over the gross } \\
\text { section due to the prestressed force }\end{array}$ \\
\hline$\varepsilon_{f}$ & tensile strain of GFRP bars & $\sigma_{c, m}^{p r e}$ & $\begin{array}{l}\text { average compressive stress over the section due } \\
\text { to the prestressed force and its moment }\end{array}$ \\
\hline $\bar{\varepsilon}_{f}$ & $\begin{array}{l}\text { mean tensile strain of GFRP bars at distance } \\
\text { between two consecutive cracks }\end{array}$ & $\sigma_{s r}$ & $\begin{array}{l}\text { tensile stress of reinforcements at crack } \\
\text { formation stage defined by Eq. ( } 43 \text { ) }\end{array}$ \\
\hline$\varepsilon_{f}^{p r e}$ & pre-strain of GFRP bars & $\chi_{c r}^{h}$ & $\begin{array}{l}\text { the curvature of cracked section corresponding } \\
\text { to } M_{n}\end{array}$ \\
\hline$\varepsilon_{f u}$ & the ultimate tensile strain of GFRP bars & $\phi_{f}$ & diameter of GFRP bars \\
\hline$\varepsilon_{f}^{u}$ & $\begin{array}{l}\text { upper limit of GFRP bar tensile strain during } \\
\text { the first fatigue cycle }\end{array}$ & $\phi_{s}$ & diameter of steel strand \\
\hline$\varepsilon_{s}$ & tensile strain of steel strand & $\phi_{s f}$ & diameter of steel fibers \\
\hline
\end{tabular}




\section{List of Tables}

Table 1: Nominal properties of the longitudinal reinforcements used in the present study Table 2: SFRSCC composition

Table 3: The residual flexural tensile strength parameters of SFRSCC

Table 4: Beam identification, reinforcement data of GFRP and steel bars and prestress level Table 5: Pre-strain losses on the prestressed beams for Group B of tests

Table 6: The balanced reinforcement ratio and the nominal flexural strength of the tested beams

Table 7: Flexural strength of the tested beams from the experiments and theoretical methods 
Table 1: Nominal properties of the longitudinal reinforcements used in the present study

\begin{tabular}{|c|c|c|c|c|c|c|c|c|}
\hline \multirow[b]{2}{*}{ Type } & Diameter & $\begin{array}{l}\text { Cross section } \\
\text { area }\end{array}$ & $\begin{array}{l}\text { Young's } \\
\text { Modulus }\end{array}$ & $\begin{array}{l}\text { Yielding } \\
\text { strain }\end{array}$ & $\begin{array}{l}\text { Yielding } \\
\text { stress }\end{array}$ & $\begin{array}{l}\text { Ultimate } \\
\text { stress }\end{array}$ & $\begin{array}{l}\text { Ultimate } \\
\text { strain }\end{array}$ & Weight \\
\hline & $\begin{array}{c}\phi_{f}, \phi_{s} \\
(\mathrm{~mm})\end{array}$ & $\begin{array}{l}A_{f}, A_{s} \\
\left(\mathrm{~mm}^{2}\right)\end{array}$ & $\begin{array}{c}E_{f}, E_{s} \\
(\mathrm{GPa})\end{array}$ & $\begin{array}{l}\varepsilon_{s y} \\
(\%)\end{array}$ & $\begin{array}{c}f_{s y} \\
(\mathrm{MPa})\end{array}$ & $\begin{array}{c}f_{f u}, f_{s u} \\
(\mathrm{MPa})\end{array}$ & $\begin{array}{c}\varepsilon_{f u}, \varepsilon_{s u} \\
(\%)\end{array}$ & $(\mathrm{gr} / \mathrm{m})$ \\
\hline Steel strand 15 & 15.2 & 139.4 & 187.5 & $\sim 0.85$ & $\sim 1600$ & $\sim 1900$ & $>3.5$ & 1094 \\
\hline Steel strand 9 & 9.5 & 51.6 & 187.5 & $\sim 0.85$ & $\sim 1600$ & $\sim 1900$ & $>3.5$ & 405 \\
\hline GFRP bar & 13.1 & 134.7 & 60.0 & - & - & 1350 & 2.25 & 317 \\
\hline
\end{tabular}

${ }^{1}$ The subscript "s" refers to the parameters for steel strand, and "f" for GFRP bars; 
Table 2: SFRSCC composition

\begin{tabular}{|c|c|c|c|c|c|c|c|c|}
\hline $\begin{array}{l}\text { Cement } \\
(\mathrm{kg} / \mathrm{m} 3)\end{array}$ & $\begin{array}{l}\text { Fly ash } \\
\left(\mathrm{kg} / \mathrm{m}^{3}\right)\end{array}$ & $\begin{array}{c}\text { Limestone } \\
\text { filler } \\
\left(\mathrm{kg} / \mathrm{m}^{3}\right)\end{array}$ & $\begin{array}{c}\text { Water } \\
\left(\text { Liter } / \mathrm{m}^{3}\right)\end{array}$ & $\begin{array}{c}\text { SP* } \\
\left(\text { Liter } / \mathrm{m}^{3}\right)\end{array}$ & $\begin{array}{c}\text { Fine } \\
\text { sand } \\
\left(\mathrm{kg} / \mathrm{m}^{3}\right)\end{array}$ & $\begin{array}{l}\text { Coarse } \\
\text { Sand } \\
\left(\mathrm{kg} / \mathrm{m}^{3}\right)\end{array}$ & $\begin{array}{c}\text { Coarse } \\
\text { Aggregate } \\
\left(\mathrm{kg} / \mathrm{m}^{3}\right)\end{array}$ & $\begin{array}{c}\mathbf{S T}^{* *} \\
\left(\mathrm{~kg} / \mathrm{m}^{3}\right)\end{array}$ \\
\hline 472 & 141 & 142 & 201 & 16 & 123 & 656 & 503 & 90 \\
\hline
\end{tabular}

** ST: Steel fiber of $33 \mathrm{~mm}$ length $\left(l_{s f}\right), 0.5 \mathrm{~mm}$ diameter $\left(\phi_{s f}\right)$, and 65 of aspect ratio; 
Table 3: The residual flexural tensile strength parameters of SFRSCC

\begin{tabular}{|c|c|c|c|c|c|c|c|c|c|c|c|}
\hline & \multicolumn{8}{|c|}{ Residual flexural tensile strength parameters } & \multirow{2}{*}{\multicolumn{2}{|c|}{$\begin{array}{c}\text { Limit of } \\
\text { proportionality* }\end{array}$}} & \multirow[b]{3}{*}{$\begin{array}{l}f_{F s t}^{* *} \\
(\mathrm{MPa}) \\
\end{array}$} \\
\hline & \multicolumn{2}{|c|}{$C M O D_{1}$} & \multicolumn{2}{|c|}{$\mathrm{CMOD}_{2}$} & \multicolumn{2}{|c|}{$\mathrm{CMOD}_{3}$} & \multicolumn{2}{|c|}{$\mathrm{CMOD}_{4}$} & & & \\
\hline & $\begin{array}{c}F_{1} \\
(\mathrm{kN}) \\
\end{array}$ & $\begin{array}{c}f_{R, 1} \\
(\mathrm{MPa})\end{array}$ & $\begin{array}{c}F_{2} \\
(\mathrm{kN})\end{array}$ & $\begin{array}{l}f_{R, 2} \\
(\mathrm{MPa}) \\
\end{array}$ & $\begin{array}{c}F_{3} \\
(\mathrm{kN}) \\
\end{array}$ & $\begin{array}{c}f_{R, 3} \\
(\mathrm{MPa}) \\
\end{array}$ & $\begin{array}{c}F_{4} \\
(\mathrm{kN}) \\
\end{array}$ & $\begin{array}{c}f_{R, 4} \\
(\mathrm{MPa}) \\
\end{array}$ & $\begin{array}{c}F_{L} \\
(\mathrm{kN}) \\
\end{array}$ & $\begin{array}{c}f_{c t, L} \\
(\mathrm{MPa}) \\
\end{array}$ & \\
\hline Average & 30.65 & 11.59 & 30.81 & 11.65 & 28.25 & 10.68 & 25.26 & 9.55 & 15.57 & 5.90 & 5.21 \\
\hline $\operatorname{CoV}(\%)$ & & 21 & & 04 & & 80 & & 39 & & & \\
\hline
\end{tabular}

${ }^{*}$ Calculated by Eq. (1) for CMOD $=0.05 \mathrm{~mm}$;

** this value is used for calculation of crack width in section 3.7 , and it is equal to $0.45 f_{R, 1}$ according to [24]. 
Table 4: Beam identification, reinforcement data of GFRP and steel bars and prestress level

\begin{tabular}{|c|c|c|c|c|c|c|c|c|c|c|c|c|c|}
\hline & \multirow{3}{*}{$\begin{array}{l}\text { Beam } \\
\text { ID }\end{array}$} & & & & & & & \multicolumn{6}{|c|}{ Close to jacking } \\
\hline & & \multicolumn{2}{|c|}{$A_{f}$} & \multirow{2}{*}{$\frac{\rho_{f}}{(\%)}$} & \multicolumn{2}{|c|}{$A_{s}$} & \multirow{2}{*}{$\frac{\rho_{s}}{(\%)}$} & \multicolumn{2}{|c|}{$f_{s}^{p r e}$} & \multicolumn{2}{|c|}{$f_{f}^{p r e}$} & \multirow{2}{*}{$\frac{N_{p s}{ }^{*}}{(\mathrm{kN})}$} & \multirow{2}{*}{$\frac{N_{p f}{ }^{* *}}{(\mathrm{kN})}$} \\
\hline & & $\left(\mathrm{mm}^{2}\right)$ & & & $\left(\mathrm{mm}^{2}\right)$ & & & $(\mathrm{MPa})$ & $(\%)$ & (MPa) & $(\%)$ & & \\
\hline \multirow{4}{*}{ 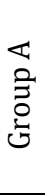 } & IB1 & 269 & $2 \varnothing 12$ & 0.29 & 139.0 & $1 \varnothing 15$ & 0.18 & 0.0 & 0 & 0 & 0 & 0.0 & 0.0 \\
\hline & IB2 & 269 & $2 \emptyset 12$ & 0.29 & 139.0 & $1 \varnothing 15$ & 0.18 & 400 & 25 & 0 & 0 & 55.6 & 0.0 \\
\hline & IB3 & 269 & $2 \varnothing 12$ & 0.29 & 139.0 & $1 \varnothing 15$ & 0.18 & 800 & 50 & 0 & 0 & 111.2 & 0.0 \\
\hline & IB4 & 404 & $3 \emptyset 12$ & 0.43 & 139.0 & $1 \varnothing 15$ & 0.18 & 800 & 50 & 0 & 0 & 111.2 & 0.0 \\
\hline \multirow{6}{*}{ 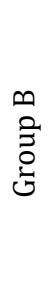 } & IB5 & 269 & $2 \varnothing 12$ & 0.29 & 51.6 & $1 \emptyset 9$ & 0.07 & 0.0 & 0 & 0 & 0 & 0.0 & 0.0 \\
\hline & IB6 & 269 & $2 \emptyset 12$ & 0.29 & 51.6 & $1 \varnothing 9$ & 0.07 & 800 & 50 & 200 & 15 & 41.3 & 53.8 \\
\hline & $\mathrm{IB}^{* * *}$ & 269 & $2 \varnothing 12$ & 0.29 & 51.6 & $1 \varnothing 9$ & 0.07 & 800 & 50 & 200 & 15 & 41.3 & 53.8 \\
\hline & IB8 & 269 & $2 \emptyset 12$ & 0.29 & 51.6 & $1 \varnothing 9$ & 0.07 & 800 & 50 & 400 & 30 & 41.3 & 107.6 \\
\hline & IB9 $9^{* * *}$ & 269 & $2 \emptyset 12$ & 0.29 & 51.6 & $1 \varnothing 9$ & 0.07 & 800 & 50 & 400 & 30 & 41.3 & 107.6 \\
\hline & IB10 $0^{* * *}$ & 269 & $2 \varnothing 12$ & 0.29 & 51.6 & $1 \varnothing 9$ & 0.07 & 800 & 50 & 540 & 40 & 41.3 & 145.3 \\
\hline
\end{tabular}

\footnotetext{
${ }^{*}$ Prestressed force in the steel strand without considering pre-strain losses;

** Prestressed force in the GFRP bars without considering pre-strain losses;
}

${ }^{* * *}$ Beams used in fatigue loading tests. 
Table 5: Pre-strain losses on the prestressed beams for Group B of tests

\begin{tabular}{|c|c|c|c|c|c|c|c|c|c|c|}
\hline \multirow[t]{2}{*}{$\begin{array}{c}\text { Beam } \\
\text { ID }\end{array}$} & \multirow[t]{2}{*}{$\begin{array}{c}\text { Design prestress } \\
\text { level }^{1}\end{array}$} & \multirow[t]{2}{*}{$\begin{array}{l}\text { Design Pre- } \\
\text { strain } \\
\text { level }^{2}\end{array}$} & \multirow[t]{2}{*}{$\begin{array}{c}\text { Reinforcing } \\
\text { line }\end{array}$} & \multicolumn{5}{|c|}{$\begin{array}{c}\text { Average value of strain in the } \\
\text { reinforcements } \\
\varepsilon_{s}^{\text {pre }} \text { and } \varepsilon_{f}^{\text {pre }} \text { at }\end{array}$} & \multirow[t]{2}{*}{ Loss } & \multirow{2}{*}{$\begin{array}{l}\text { Prestress } \\
\quad \text { level }{ }^{3} \\
P_{p s} \text { or } P_{p f}\end{array}$} \\
\hline & & & & $\begin{array}{c}\text { Pulling } \\
(\%)\end{array}$ & $\begin{array}{c}\rightarrow \\
\text { days }\end{array}$ & $\begin{array}{c}\text { Releasing } \\
(\%) \\
\end{array}$ & $\begin{array}{c}\rightarrow \\
\text { days }\end{array}$ & $\begin{array}{c}\text { Testing } \\
\text { day } \\
(\%)\end{array}$ & & \\
\hline \multirow{3}{*}{ IB6 } & 50 & 0.43 & Steel & 0.44 & 4 & 0.41 & 95 & 0.40 & 9 & 47 \\
\hline & 15 & 0.34 & GFRP 1 & 0.35 & 4 & 0.33 & 95 & 0.30 & 14 & 13 \\
\hline & 15 & 0.34 & GFRP 2 & 0.37 & 4 & 0.36 & 95 & 0.32 & 14 & 14 \\
\hline \multirow{3}{*}{ IB7 } & 50 & 0.43 & Steel & 0.46 & 4 & 0.45 & 94 & 0.41 & 11 & 48 \\
\hline & 15 & 0.34 & GFRP 1 & 0.35 & 4 & 0.34 & 94 & 0.30 & 14 & 13 \\
\hline & 15 & 0.34 & GFRP 2 & 0.36 & 4 & 0.34 & 94 & 0.31 & 14 & 14 \\
\hline \multirow{3}{*}{ IB8 } & 50 & 0.43 & Steel & 0.45 & 4 & 0.44 & 93 & 0.41 & 9 & 48 \\
\hline & 30 & 0.68 & GFRP 1 & 0.68 & 4 & 0.65 & 93 & 0.58 & 15 & 25 \\
\hline & 30 & 0.68 & GFRP 2 & 0.69 & 4 & 0.67 & 93 & 0.60 & 13 & 26 \\
\hline \multirow{3}{*}{ IB9 } & 50 & 0.43 & Steel & 0.45 & 4 & 0.42 & 126 & 0.40 & 11 & 47 \\
\hline & 30 & 0.68 & GFRP 1 & 0.69 & 4 & 0.67 & 126 & 0.60 & 13 & 26 \\
\hline & 30 & 0.68 & GFRP 2 & 0.68 & 4 & 0.63 & 126 & 0.58 & 15 & 25 \\
\hline \multirow{5}{*}{ IB10 } & 50 & 0.43 & Steel & 0.45 & 4 & 0.44 & 122 & 0.41 & 9 & 48 \\
\hline & 40 & 0.90 & GFRP 1 & 0.94 & 4 & 0.88 & 122 & 0.83 & 11 & 37 \\
\hline & 40 & 0.90 & GFRP 2 & 0.93 & 4 & 0.86 & 122 & 0.81 & 14 & 36 \\
\hline & & & & & & \multirow{2}{*}{\multicolumn{2}{|c|}{ Average: }} & Steel & $9.8 \%$ & \\
\hline & & & & & & & & GFRP & $13.6 \%$ & \\
\hline
\end{tabular}

${ }^{1}$ It is defined as the value in percentage that is calculated by dividing the nominal prestress value in the reinforcements by the yield stress in case of steel strand and by the ultimate tensile stress in case of GFRP bar;

${ }^{2}$ It is defined as the strain value in percentage calculating by multiplying the design prestress level by the yield strain in case of steel strand and the ultimate tensile strain in case of GFRP bar;

${ }^{3}$ It is calculated according to the value of prestress in the reinforcements after the losses being occurred; 
Table 6: The balanced reinforcement ratio and the nominal flexural strength of the tested beams

\begin{tabular}{|c|c|c|c|c|c|c|c|c|c|c|c|}
\hline \multirow{4}{*}{$\underset{\varpi}{\Xi}$} & & \multicolumn{4}{|c|}{$\begin{array}{c}\text { Balanced reinforcement } \\
\text { ratio }\end{array}$} & \multicolumn{4}{|c|}{ Nominal flexural strength } & \multirow{3}{*}{$\begin{array}{c}\text { By } \\
\text { DoCROS } \\
\rho_{f}^{u p} * \\
\end{array}$} & \multirow{4}{*}{$\begin{array}{l}\text { Over/under } \\
\text { reinforced }\end{array}$} \\
\hline & & \multicolumn{2}{|c|}{$\begin{array}{l}\text { By Eqs. (5) } \\
\text { and (10) }\end{array}$} & \multicolumn{2}{|c|}{ By DOCROS } & \multicolumn{2}{|c|}{$\begin{array}{l}\text { By Eq. (19) } \\
\text { or (22) }\end{array}$} & \multicolumn{2}{|c|}{ By DOCROS } & & \\
\hline & $\rho_{f}$ & $c_{b}$ & $\rho_{f b}$ & $c_{b}$ & $\rho_{f b}$ & $c$ & $M_{n}$ & $c$ & $M_{n}$ & & \\
\hline & $(\%)$ & $(\mathrm{mm})$ & $(\%)$ & $(\mathrm{mm})$ & $(\%)$ & $(\mathrm{mm})$ & (kN.m) & $(\mathrm{mm})$ & (kN.m) & $(\%)$ & \\
\hline IB1 & 0.29 & 63.3 & 0.25 & 66.2 & 0.23 & 67.3 & 265.4 & 70.6 & 257.1 & 1.28 & $\sim$ Balanced \\
\hline IB2 & 0.29 & 63.3 & 0.25 & 66.2 & 0.23 & 67.3 & 265.4 & 70.5 & 257.4 & 1.97 & $\sim$ Balanced \\
\hline IB3 & 0.29 & 63.3 & 0.25 & 66.2 & 0.23 & 67.3 & 265.4 & 70.5 & 257.2 & 3.24 & $\sim$ Balanced \\
\hline IB4 & 0.43 & 63.3 & 0.25 & 66.2 & 0.23 & 75.5 & 309.7 & 80.2 & 297.1 & 3.24 & Over \\
\hline IB5 & 0.29 & 63.5 & 0.36 & 66.2 & 0.33 & 58.8 & 226.7 & 61.6 & 218.7 & - & Under \\
\hline IB6,7 & 0.29 & 71.5 & 0.42 & 75.1 & 0.40 & 61.9 & 226.1 & 65.7 & 221.3 & - & Under \\
\hline IB8,9 & 0.29 & 81.8 & 0.48 & 86.1 & 0.48 & 66.8 & 225.0 & 70.5 & 223.6 & - & Under \\
\hline IB10 & 0.29 & 94.0 & 0.54 & 98.2 & 0.56 & 72.6 & 223.9 & 75.4 & 225.1 & - & Under \\
\hline
\end{tabular}

* the upper limit of FRP reinforcement ratio in which for $\rho_{f}>\rho_{f}^{u p}$, concrete crushing occurs prior to yielding of steel in tension. 
Table 7: Flexural strength of the tested beams from the experiments and theoretical methods

\begin{tabular}{|c|c|c|c|c|c|c|c|c|c|c|}
\hline \multirow{3}{*}{ 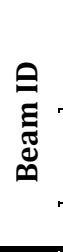 } & \multicolumn{2}{|c|}{$\begin{array}{l}\text { By experimental } \\
\text { results }\end{array}$} & \multicolumn{2}{|c|}{$\begin{array}{c}\text { Recommended by } \\
\text { CEB-FIB } \#\end{array}$} & \multirow{2}{*}{$\begin{array}{c}\text { By } \\
\text { Eq. (19) } \\
\text { or (22) } \\
M_{n}\end{array}$} & \multirow{2}{*}{$\frac{\begin{array}{c}\text { By } \\
\text { DoCROS }\end{array}}{M_{y}^{\dagger}}$} & \multirow{2}{*}{$\begin{array}{c}\begin{array}{c}\text { By Def- } \\
\text { DOCROS }\end{array} \\
D_{y}{ }^{\dagger}\end{array}$} & \multirow{3}{*}{$\frac{M_{u, \exp }}{M_{n}}$} & \multirow{3}{*}{$\begin{array}{c}\text { Is the } \\
\text { steel } \\
\text { yielded? }\end{array}$} & \multirow{3}{*}{$\begin{array}{l}\text { Mode } \\
\text { of failure }\end{array}$} \\
\hline & $M_{u, \exp }$ & $M_{S L S}{ }^{*}$ & $V_{c d}$ & $M_{c d}$ & & & & & & \\
\hline & (kN.m) & (kN.m) & $(\mathrm{kN})$ & (kN.m) & (kN.m) & (kN.m) & $(\mathrm{mm})$ & & & \\
\hline IB1 & 175 & 111 & 49.5 & 73.0 & 270 & 214 & 36 & 0.66 & No & Shear failure \\
\hline IB2 & 179 & 119 & 53.2 & 78.5 & 270 & 202 & 32 & 0.68 & No & Shear failure \\
\hline IB3 & 180 & 132 & 56.8 & 83.8 & 270 & 189 & 31 & 0.68 & No & Shear failure \\
\hline IB4 & 142 & 135 & 60.3 & 88.9 & 302 & 242 & 30 & 0.47 & No & Shear failure \\
\hline IB5 & 148 & 100 & 42.6 & 68.2 & 223 & 165 & 36 & 0.67 & No & Shear failure \\
\hline IB6 & 186 & 128 & 49.5 & 79.2 & 226 & 155 & 21 & 0.83 & Yes & Flexo shear failure \\
\hline IB8 & 201 & 147 & 52.8 & 84.5 & 229 & 175 & 20 & 0.89 & Yes & Flexo shear failure \\
\hline IB10 & $210^{\S}$ & 157 & 55.6 & 89.0 & 227 & 190 & 19 & 0.93 & Yes & Flexo shear failure \\
\hline
\end{tabular}

"calculated from the experimental results of force-deflection corresponding to the mid-span deflection of about $L / 250 \sim 15 \mathrm{~mm}$

\# these values are calculated based on the recommendation by CEB-FIB Model Code 2010 [24], being $M_{c d}=V_{c d}, a$;

t obtained using DOCROS software, which correspond to the steel strand tensile stress of $\sim 1600 \mathrm{MPa}$ at the pure bending zone

$\S$ obtained from the monotonic test after two million fatigue cycles. 


\section{List of Figures}

Figure 1: Dimension and reinforcing configuration of the beam specimens (dimensions in $\mathrm{mm}$ ) Figure 2: Test setup and measuring sensors used in the experimental study

Figure 3: Balanced section of SFRSCC beam reinforced by hybrid prestressed FRP-steel (not to scale)

Figure 4: Nominal flexural failing conditions of strain versus balanced section condition for hybrid reinforced SFRSCC prestressed beams

Figure 5: Material properties used in the analysis of the tested beams: (a) Compressive stressstrain, (b) tensile stress-strain, and (c) tensile stress-crack opening of SFRSCC; (d) and (e) tensile stress-strain of steel strand and GFRP bars, respectively

Figure 6: (a) Effective moment of inertia versus the maximum applied moment (b) decreasing pattern of the effective moment of inertia at cracking initiation (c) effect of flexure-shear crack propagation of SFRSCC on the decrease in the effective moment of inertia (not to scale)

Figure 7: Ultimate crack pattern and failure cracks of the tested beams in Group A (dimensions in $\mathrm{mm}$ )

Figure 8: Ultimate crack pattern and failure cracks of the tested beams in Group B (dimensions in $\mathrm{mm}$ )

Figure 9: Comparison between the theoretical and experimental effective moment of inertia: (a) Group A, (b) Group B

Figure 10: Effect of coefficient $\beta_{\text {sh }}$ on the theoretical effective moment of inertia (including comparison with the experimental result)

Figure 11: Applied moment versus mid-span deflection up to the serviceability limit state of the mid-span deflection: (a) Group A, (b) Group B

Figure 12: Applied force versus mid-span deflection of the tested beams in Group A

Figure 13: Applied force versus mid-span deflection of the tested beams in Group B

Figure 14: Comparison between the ductility index of the tested beams and the "reference response" by Def-DOCROS

Figure 15: Crack pattern of the monotonically tested beams for the mid-span deflection corresponding to SLS

Figure 16: Crack width versus the tensile stress of GFRP bars: (a) IB5, (b) IB6, (c) IB8, and (d) IB10 


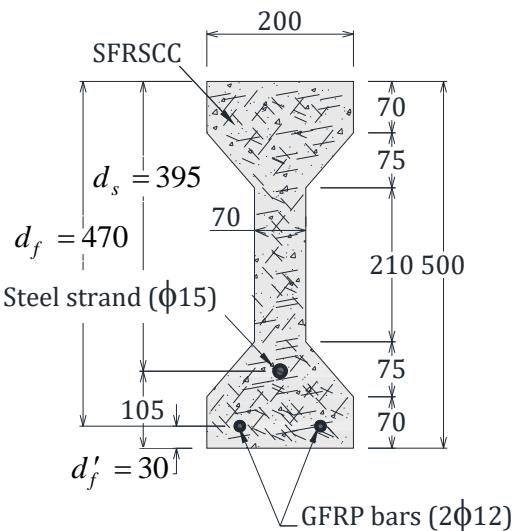

IB1, IB2, IB3

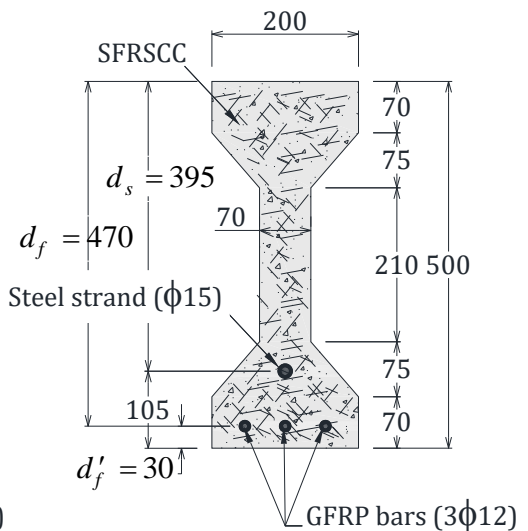

IB4

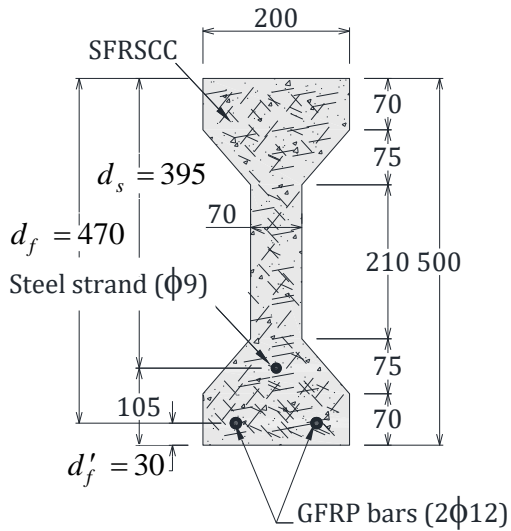

IB5, IB6, IB7

IB8, IB9, IB10

Figure 1: Dimension and reinforcing configuration of the beam specimens (dimensions in mm) 


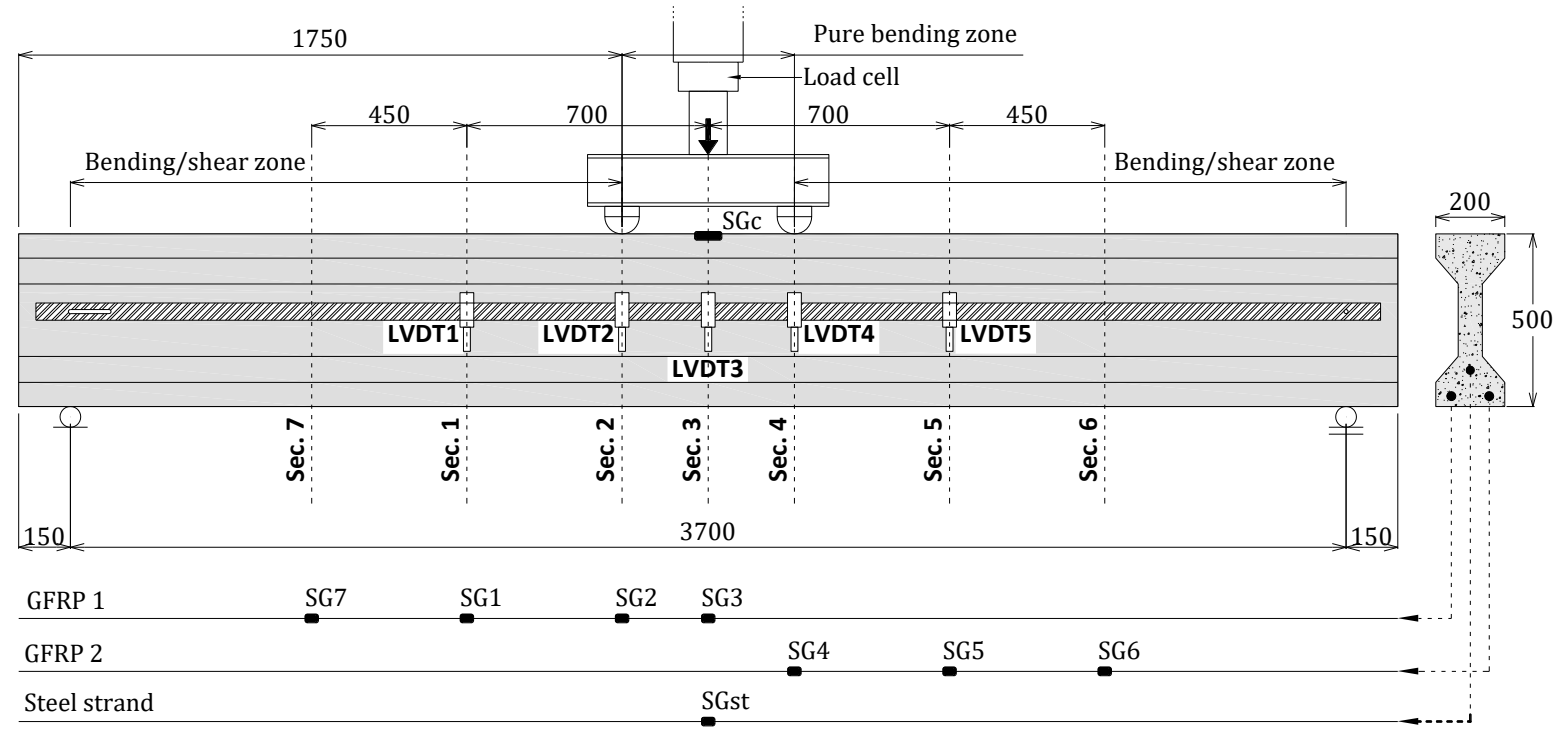

Figure 2: Test setup and measuring sensors used in the experimental study 




Figure 3: Balanced section of SFRSCC beam reinforced by hybrid prestressed FRP-steel (not to scale) 


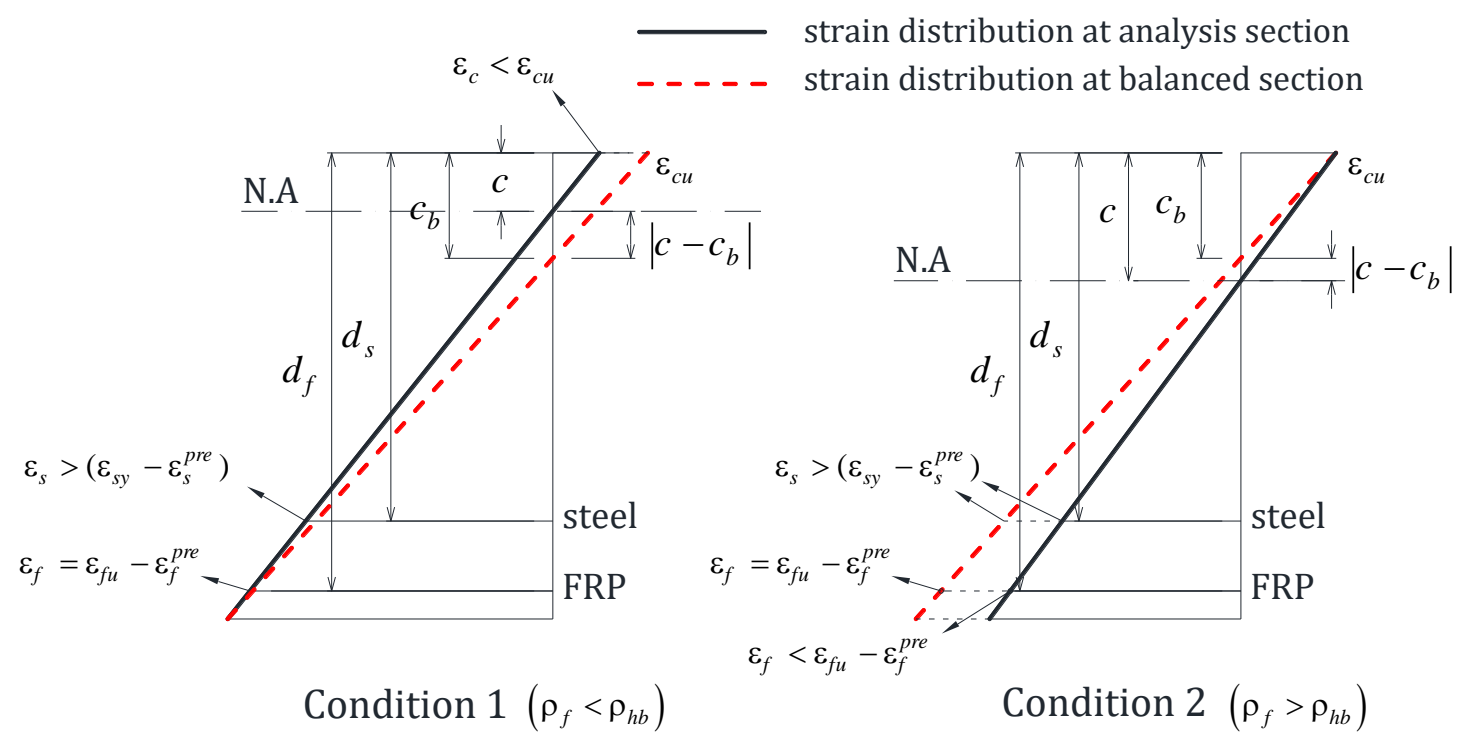

Figure 4: Nominal flexural failing conditions of strain versus balanced section condition for hybrid reinforced SFRSCC prestressed beams 



Figure 5: Material properties used in the analysis of the tested beams: (a) Compressive stress-strain, (b) tensile stress-strain, and (c) tensile stress-crack opening of SFRSCC; $(d)$ and (e) tensile stress-strain of steel strand and GFRP bars, respectively 


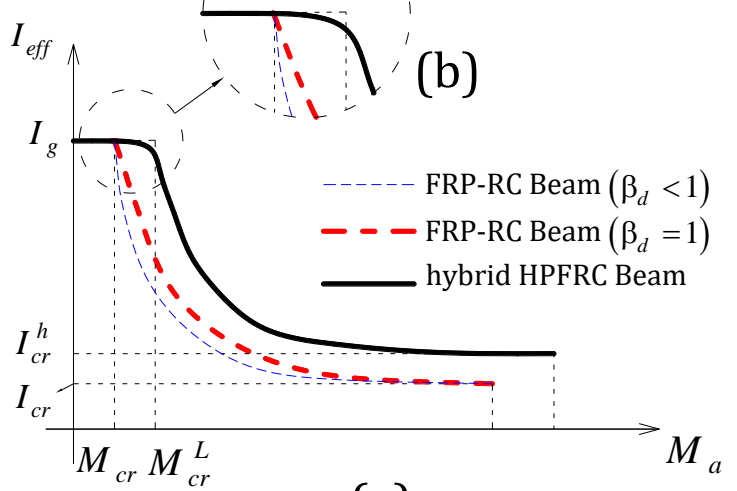

(a)



(c)

Figure 6: (a) Effective moment of inertia versus the maximum applied moment (b) decreasing pattern of the effective moment of inertia at cracking initiation (c) effect of flexure-shear crack propagation of SFRSCC on the decrease in the effective moment of inertia (not to scale) 

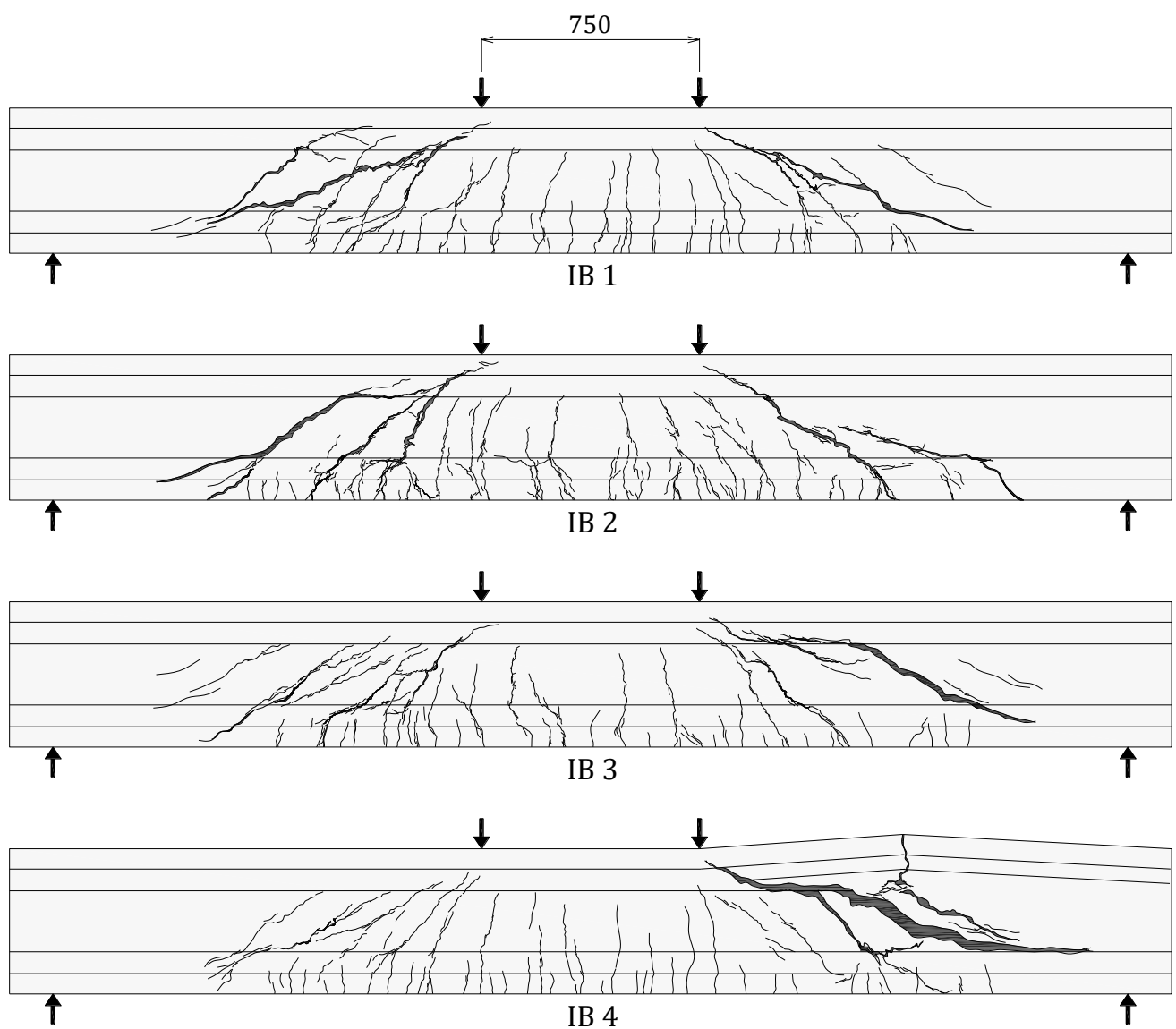

Figure 7: Ultimate crack pattern and failure cracks of the tested beams in Group A (dimensions in mm) 

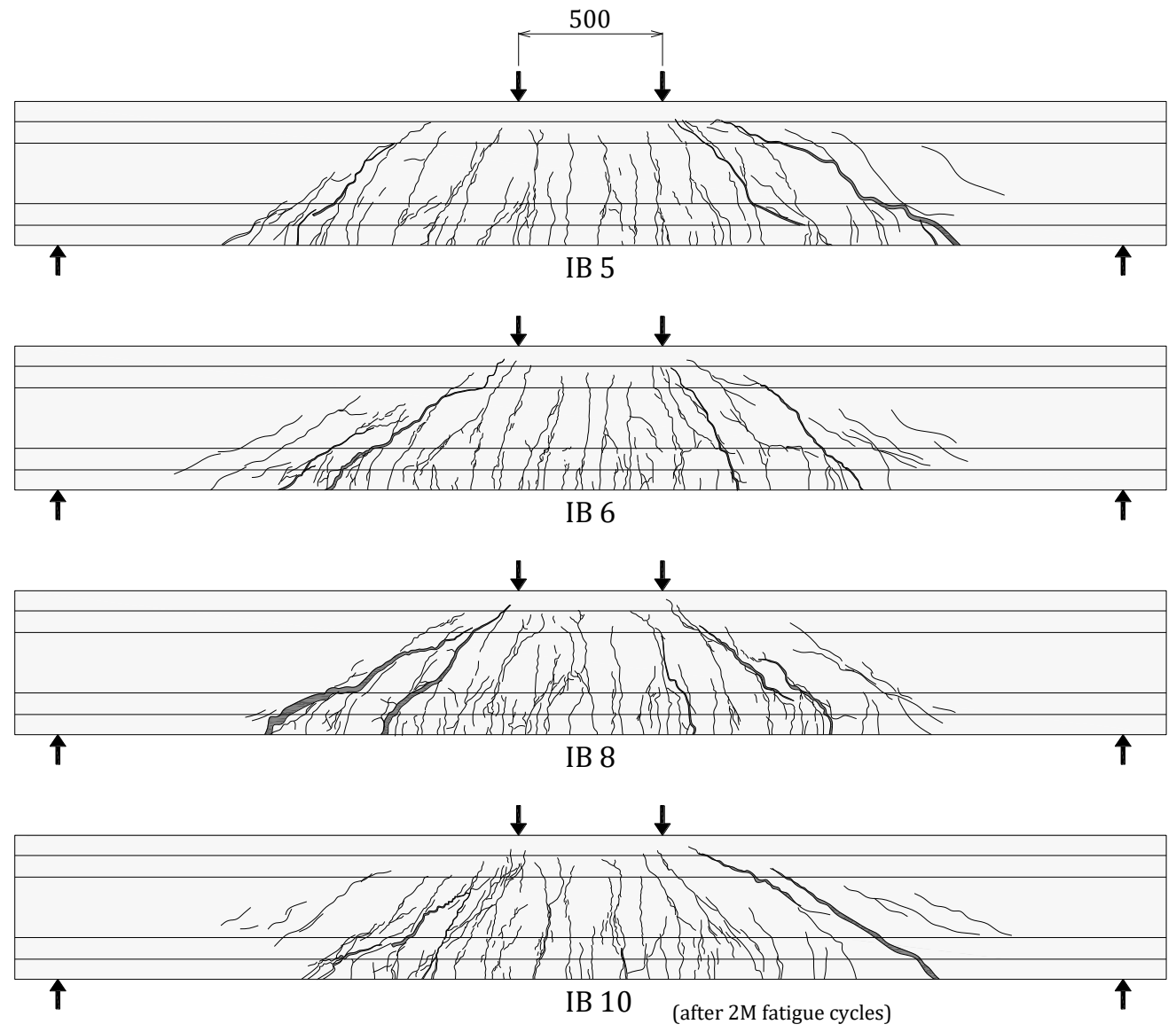

Figure 8: Ultimate crack pattern and failure cracks of the tested beams in Group B (dimensions in mm) 

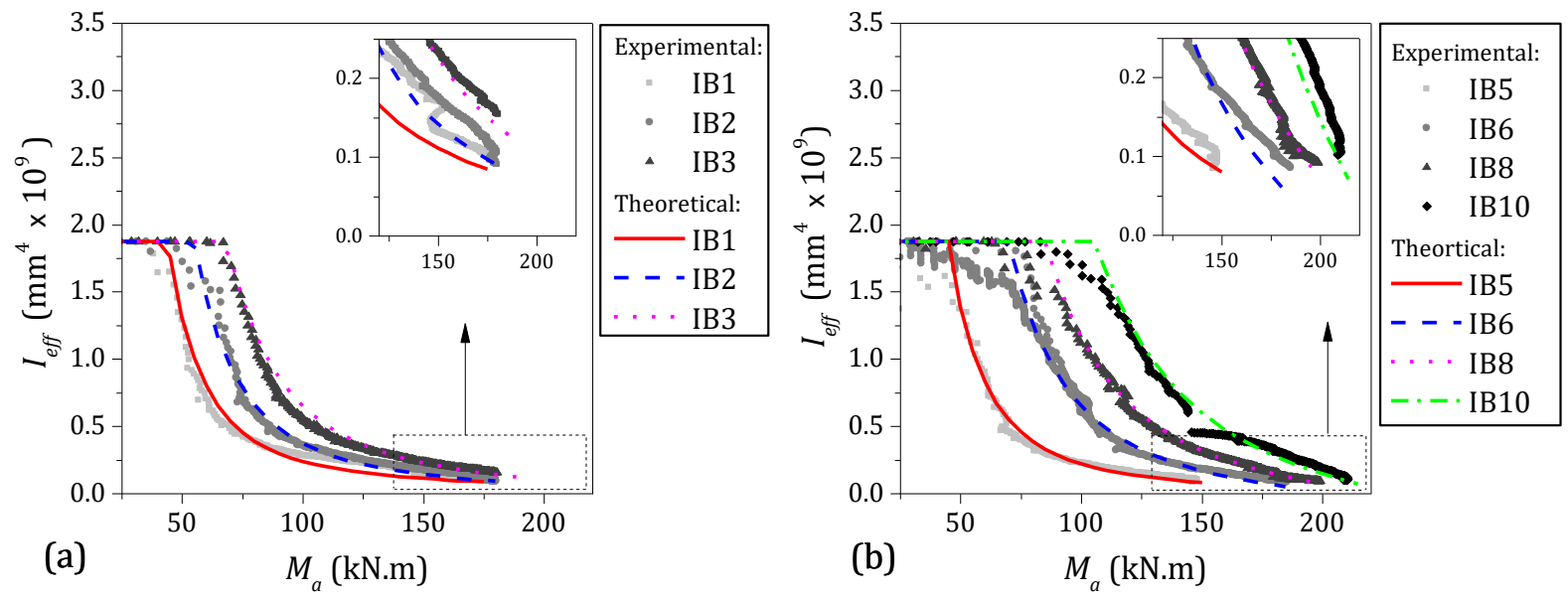

Figure 9: Comparison between the theoretical and experimental effective moment of inertia: (a) Group A, (b) Group B 


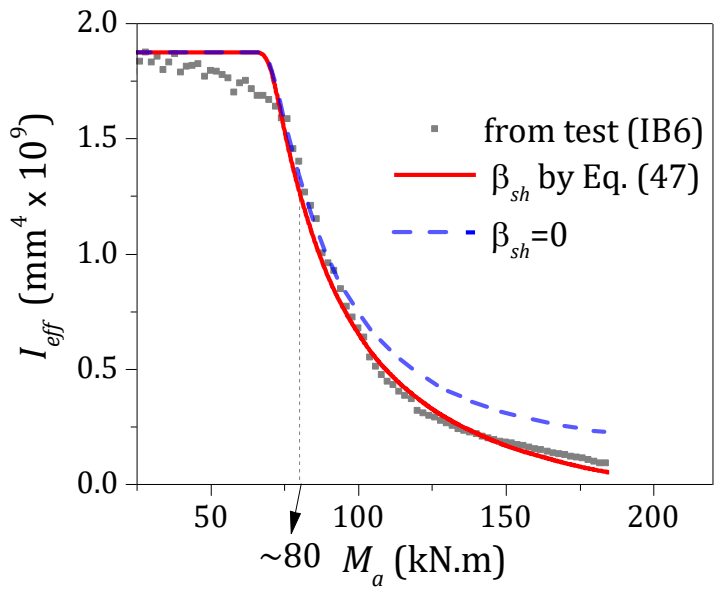

Figure 10: Effect of coefficient $\beta_{\text {sh }}$ on the theoretical effective moment of inertia (including comparison with the experimental result) 

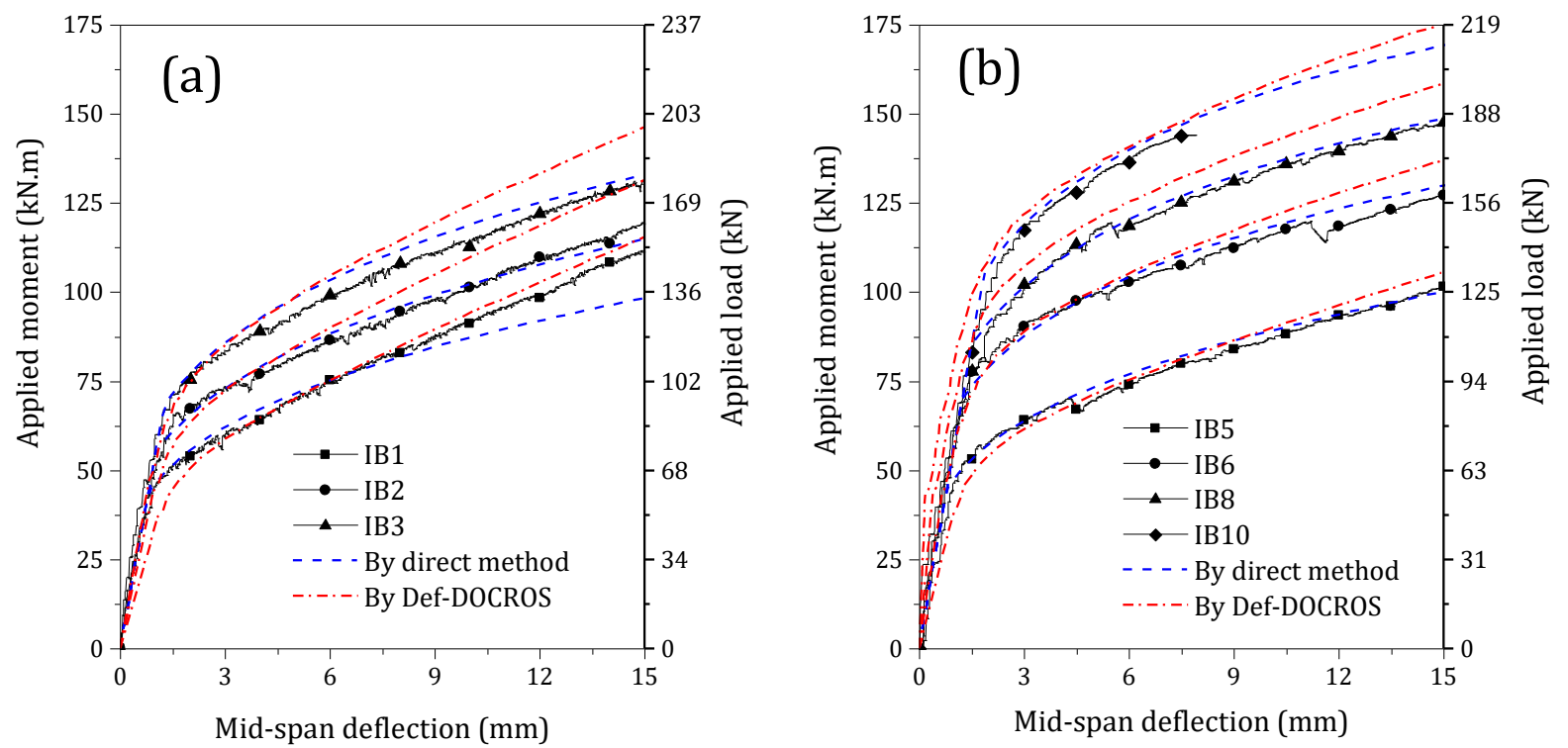

Figure 11: Applied moment versus mid-span deflection up to the serviceability limit state of the mid-span deflection: (a) Group A, (b) Group B 

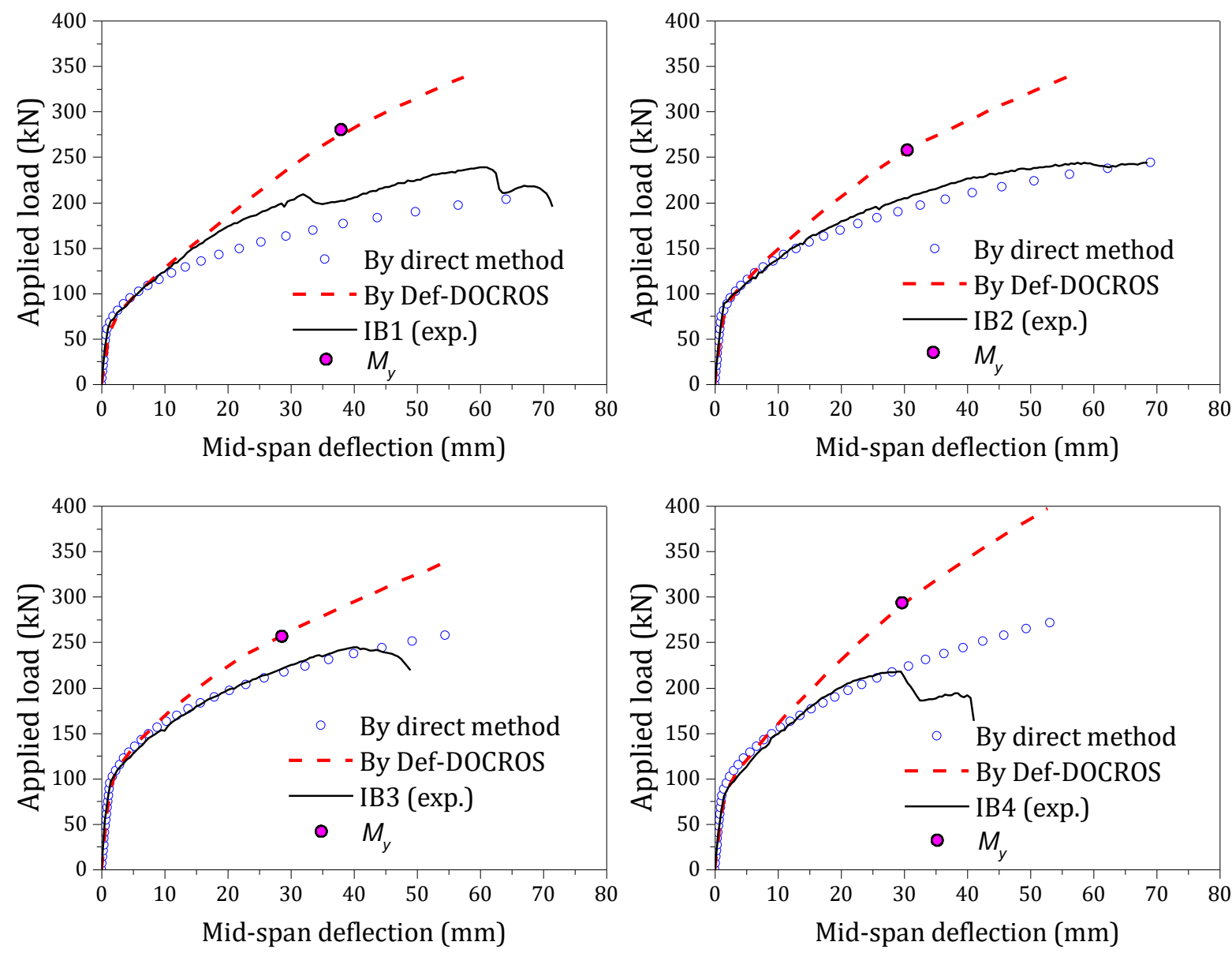

Figure 12: Applied force versus mid-span deflection of the tested beams in Group A 

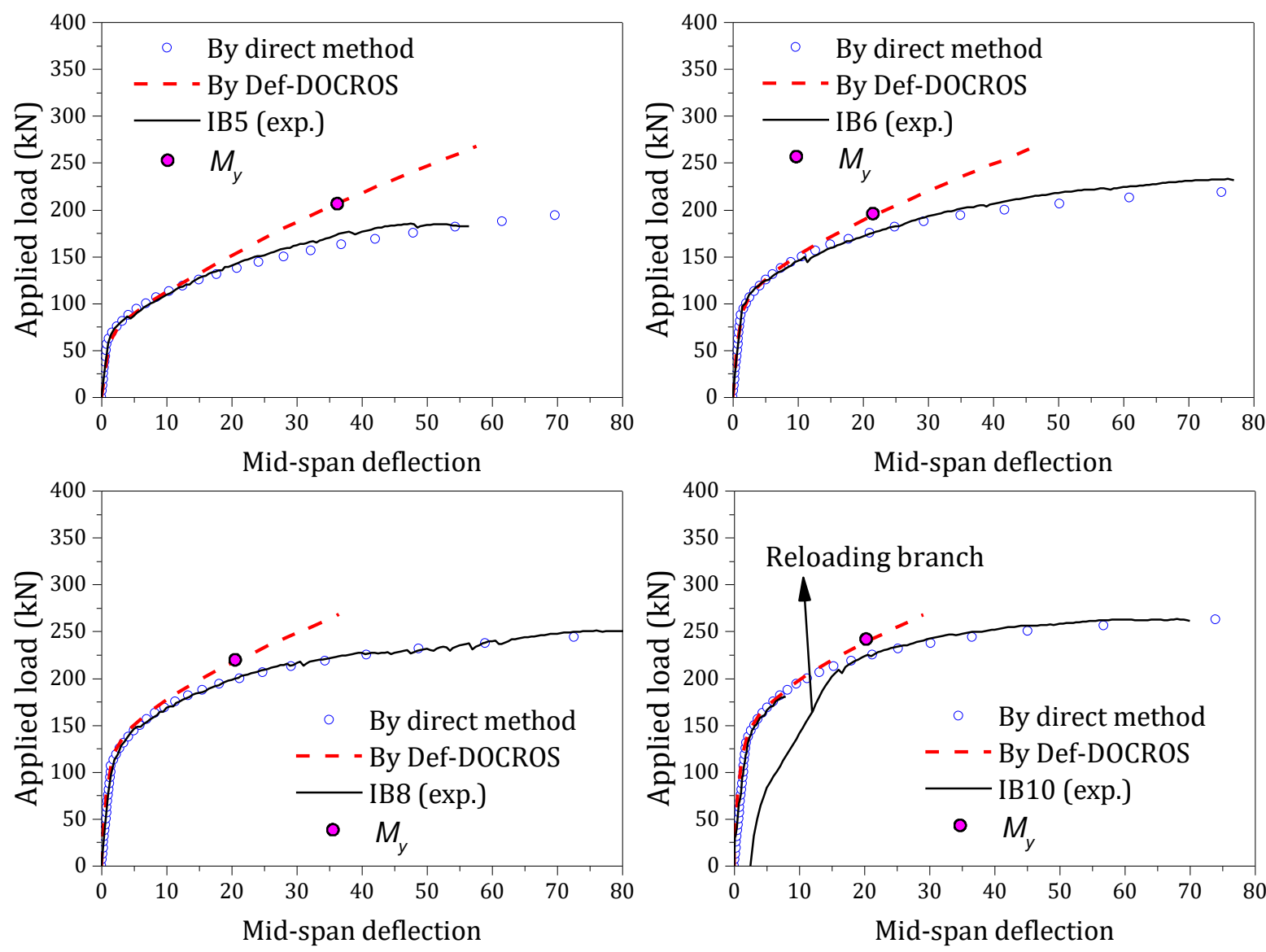

Figure 13: Applied force versus mid-span deflection of the tested beams in Group B 

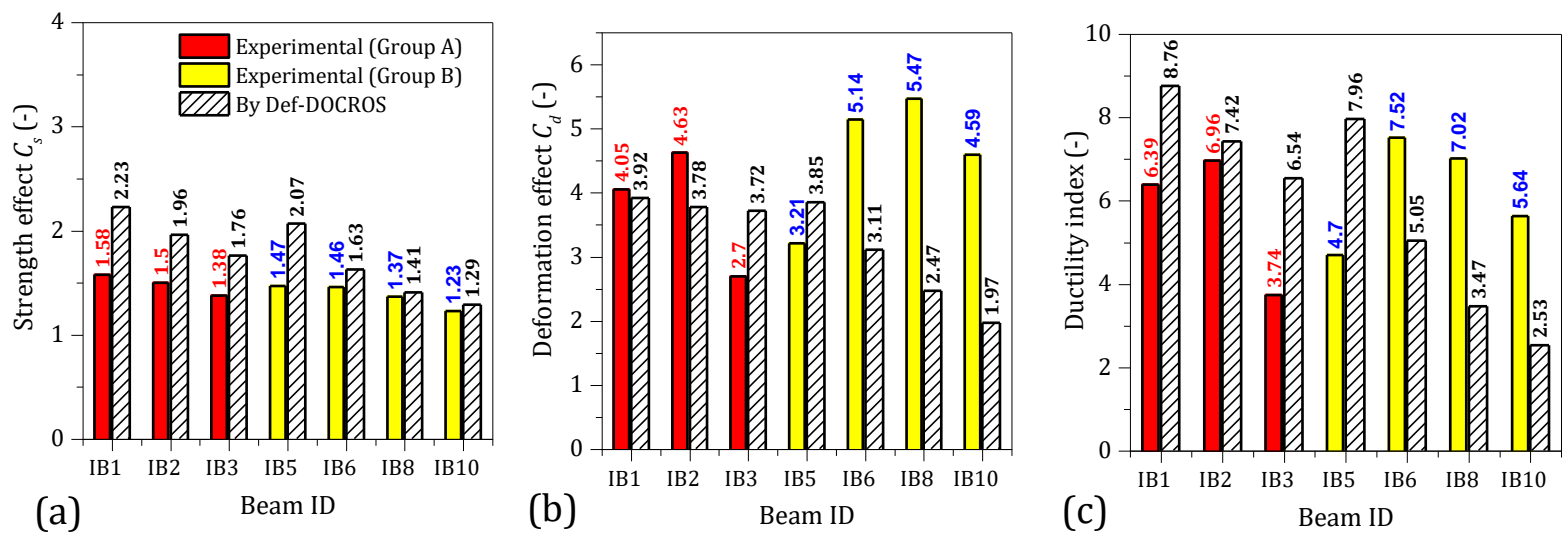

Figure 14: Comparison between the ductility index of the tested beams and the "reference response" by Def-DOCROS 




Figure 15: Crack pattern of the monotonically tested beams for the mid-span deflection corresponding to SLS 



Figure 16: Crack width versus the tensile stress of GFRP bars: (a) IB5, (b) IB6, (c) IB8, and (d) IBI0 